\title{
Maternal and Foetal Outcome in Premature Rupture of Membranes
}

\author{
Dr. Shweta Patil ${ }^{1}$, Dr. Vikram Patil ${ }^{2}$ \\ 1 Senior resident, 2 Post graduate Resident. ESI medical college, Dist Gulbarga - 585105, Karnataka, India ${ }^{1}$ \\ SSIMS \& RC Medical College, Dist. Davangere - 577001, Karnataka, India ${ }^{2}$
}

\begin{abstract}
:
Objective: The aim of this study was to see the maternal and fetal outcome of preterm pre labor rupture membrane and to identify the risk factors for preterm pre labor rupture membrane.

Methods And Material: This was a comparative study between the study (PROM) and control group conducted at 2 hospitals attached to M.R.Medical College, Gulbarga in the Department of Obstetric and Gynecology. 100 pregnant women with preterm premature rupture of the membrane (gestational age 28-0 to 36-6 weeks) were included in this study. And 100 pregnant women without PROM before 37 completed weeks are taken into control

Results: The mean age of the women was $23 \pm 3.5$ years and $53 \%$ of them were primigravida. $13 \%$ was malpresentations and $10 \% \mathrm{~h} / \mathrm{o}$ recent coitus were the major risk factors. Incidence of PPROM is $33.8 \% .64 \%$ had spontaneous labor within 24 hours. $73 \%$ percent patient delivered by vaginal route and $27 \%$ patients had LSCS twenty six percent newborn suffered from respiratory distress syndrome and $14 \%$ of neonatal sepsis. $11 \%$ patients had puerperal fever and 3\% chorioamnionitis. Seven percent had early neonatal death.

Conclusion: Antenatal diagnosis to prevent PPROM by identifying the risk factors is a important tool in management. Steroid for fetal lung maturity, antibiotics to prevent fetal and maternal infection and induction and/ or augmentation of labor will speed delivery and reduce hospital stay and infection.
\end{abstract}

Keywords: Premature rupture of the membrane; Maternal and neonatal outcome; Risk factors.

\section{List Of Tables}

\begin{tabular}{|l|l|c|}
\hline Sl. No. & \multicolumn{1}{|c|}{ Title } & Page No. \\
\hline 1. & Age wise distribution & 47 \\
\hline 2. & Relational to Antenatal Care & 48 \\
\hline 3. & Parity-wise distribution & 49 \\
\hline 4. & Risk factors for PROM & 50 \\
\hline 5. & Gestational age wise distribution & 52 \\
\hline 6. & Latent period wise distribution of gestational age & 53 \\
\hline 7. & Mode of delivery & 54 \\
\hline 8. & Vaginal delivery (spontaneous versus induced) & 55 \\
\hline 9. & Indications for LSCS in study group & 56 \\
\hline 10. & Maternal morbidity & 57 \\
\hline 11. & Maternal morbidity in relation to latent period & 58 \\
\hline 12. & Neonatal morbidity & 59 \\
\hline 13. & Neonatal morbidity in relation to latent period & 60 \\
\hline 14. & NICU admission & 61 \\
\hline 15. & Neonatal death & 63 \\
\hline 16. & Birth weight wise distribution & 64 \\
\hline 17. & Relationship of birth weight with neonatal death in study group \\
\hline
\end{tabular}

List Of Figures

\begin{tabular}{|l|l|c|}
\hline Sl. No. & \multicolumn{1}{|c|}{ Title } & Page No. \\
\hline 1. & Age wise distribution & 47 \\
\hline 2. & Relational to Antenatal Care & 48 \\
\hline 3. & Parity-wise distribution & 49 \\
\hline 4. & Risk factors for PROM & 50 \\
\hline 5. & Risk factors for PROM in study group & 51 \\
\hline 6. & Gestational age wise distribution & 52 \\
\hline 7. & $\begin{array}{l}\text { Latent period wise distribution of } \\
\text { gestational age }\end{array}$ & 53 \\
\hline 8. & Mode of delivery & 54 \\
\hline 9. & Indications for LSCS in study group & 56 \\
\hline 10. & Maternal morbidity & 57 \\
\hline 11. & Maternal morbidity in relation to latent & 58 \\
\hline
\end{tabular}




\begin{tabular}{|l|l|c|}
\hline & period & \\
\hline 12. & Neonatal morbidity & 59 \\
\hline 13. & $\begin{array}{l}\text { Neonatal morbidity in relation to latent } \\
\text { period }\end{array}$ & 60 \\
\hline 14. & NICU admission & 61 \\
\hline 15. & Neonatal death & 62 \\
\hline 16. & Birth weight wise distribution & 63 \\
\hline 17. & $\begin{array}{l}\text { Relationship of birth weight with } \\
\text { neonatal death in study group }\end{array}$ & 64 \\
\hline
\end{tabular}

\section{Introduction}

Premature rupture of membrane is common occurrence with an incidence of 5-10\%. It is a significant event as it cause maternal complications, increased operative procedures, neonatal morbidity and mortality. The management of a case of premature rupture of membranes (PROM) has remained as one of the most difficult and controversial problems in obstetrics over the past several decades.

The management of premature rupture of membranes has gone through various cycles of obstetric activity from benign neglect to immediate intervention. Paralleling these cycles of activity there have been varying degrees of concern about infection. Mean while incidence has remained unabated and is still responsible for large number of neonatal mortality. The preventive treatment awaits further elucidation of etiology, not yet fully understood.

For this study it has been defined as the spontaneous rupture of membranes during pregnancy beyond 28 weeks and before 37 completed weeks. The time from the rupture of membranes to the onset of contraction is defined as the latent period. The key factor in the foetal and maternal outcome is that the diagnosis of pre labour rupture of membranes must be established. In most instances either it is obvious from the release of clear amniotic fluid from cervix or by simple laboratory test like detection of fern pattern. The key to the management is an accurate assessment of gestational age and the presence or absence of sepsis. However the management is specially difficult in preterm patient in whom the risk of foetal and maternal infection that can accompany expectant treatment has to be weighed against potiential improvement in neonatal outcome that comes with greater maturity of foetal lungs

Currently most authorities accept a plan of active management which includes prevention of infection , delay of delivery until foetal maturity is achieved, and active intervention by induction if labor is no longer preventable or if early infection is suspected.

The present study undertaken is to identify risk factors causing PROM and to study labour outcome, maternal morbidity and perinatal morbidity and mortality associated with PROM.

\section{Objectives}

1. To study risk factors causing PROM.

2. To study labor outcome in PROM.

3. To study maternal and perinatal mordity and mortality associated with PROM.

History:

\section{Review Of Literature}

There are a number of references of premature rupture of membranes in Greek and Roman obstetric literature. They are found primarily in the Ipsissima Versa of Sorenus of Ephesus. Difficult labour was associated with premature rupture of membranes and recommended use of powerful shaking sternuateries, encouragement, holding of breath and bearing down and strong smelling things. There were many instances in history of dry birth ${ }^{1}$. A woman who had daily discharge of amniotic fluid of about 5 ounces: This daily loss of fluid from vagina continued for 68 days with the loss of 21 pints of fluid. The woman was delivered of a viable child but it died shortly thereafter.

When membranes burst long before the labour, the case may be called dry labour ${ }^{2}$. In dry labour gentle cervical dilatation is lost, cervix may suffer injury, hard head pressing on cervix may cause more pain. The uterine wall applies itself to the foetal contour, which irritates the muscle to cause irregular contractions and thereby sometimes a contraction ring forms. All these factors tend to prolong labour. Carefully selected indigent patients near term who have PROM and a cervix unfavorable for induction of labor may be safely managed in a conservative manner without increased risk of maternal neonatal infection and without prolongation of hospitalization ${ }^{3}$.

Expectant management did not reduce the incidence of caesarean birth and increased chances of funisitis and new born requirements for neonatal intensive care ${ }^{4,5}$.

Administration of antibiotics were associated with reduction in maternal and neonatal morbidity and mortality ${ }^{6}$. 


\section{Definition}

The diagnosis was established whenever spontaneous rupture occurs prior to the onset of labour. ${ }^{7}$

PROM has been applied to rupture of the membranes at any time before the onset of labour irrespective of the duration of gestation . $^{\text {. }}$

PROM was defined as rupture of membranes prior' to the establishment of regular uterine contractions.

PROM was diagnosed only when a specified latent period has elapsed following Amniorrhexis occurring at anytime prior to the onset of labour; regardless of the length of gestation..$^{910}$

ROM was defined as rupture of membranes occurring atleast one hour before onset of labour ${ }^{12,13}$. PROM was defined as rupture of membranes with atleast 2 hours latent period before active labour, latent period being the time elapsing from the time of rupture of membranes to the onset of labour ${ }^{14,15}$.

One of the main problems in diagnosing PROM is the difficulty in accurately timing the onset of labour. This problem is especially true in primigravida where regular uterine contractions may not result in cervical diltation and where cervical effacement usually precedes the onset of true labour.

Spontaneous rupture of foetal membranes occurring prior to the onset of uterine contractions, which result in progressive cervical dilation ${ }^{16}$

This definition permits the following:

1. It defines the onset of labour more accurately.

2. It usually allows the physician to establish the diagnosis as soon as the patient is seen as to formulate an initial plan of management and

3. It tends to avoid the inherent in accuracy of a retrospective diagnosis after a specified latent period has elapsed. Gynaecology.

The definition is in agreement with that established by the American College of Obstetrics and

Prolonged rupture of the membranes is defined as a latency period of 24 hours or longer between the time of membrane rupture and delivery.

High leak is a term used to describe loss of amniotic fluid caused by a tear in the membranes located above the lower uterine segment.

\section{Latent Period:}

It is the time interval between rupture of the membranes and the onset of regular uterine contraction.

\section{Incidence Of Prom:}

It is difficult to obtain an accurate determination of the incidence of PROM by reviewing the literature because of the various definitions used in establishing the diagnosis.

The incidence as 6.6-13.9\% of all patients with spontaneous rupture of the membranes at least one hour prior to the onset of labour near term or earlier. ${ }^{17}$ The range of incidence as $2.7-17 \%$ with the majority falling between 7 to $12 \%$ while in Gunn's own series the incidence of spontaneous PROM was $10.7 \%$ of total number of deliveries. ${ }^{16}$ Occurrence of spontaneous PROM in $12 \%$ of all the pregnancies.

Labour occurred spontaneously with in the first 24 hours after spontaneous rupture of the foetal membranes in $51-95 \%$ of the cases reported in the literature but most authors reported figures between $80-90 \%$. When the premature birth weight infants alone were considered, the incidence of spontaneous labour in the first 24 hours dropped to approximately $35-50 \%$.

Management of PROM is facilitated with an understanding of the events responsible for its occurrence. Therefore it is appropriate to review the development, anatomy and histology of the foetal membranes.

\section{Anatomy Of Fetal Membranes:}

The human amnion either develops from the delamination of the cytotrophoblast at about the 7th or 8th day of development of the normal ovum, or it develops essentially as an extension of the fetal ectoderm of the embryonic disc ${ }^{8}$. Trophoblastic cells lined with parietal extra embryonic mesoderm constitute the chorion.

Initially amniotic cavity appears as a minute vesicle and later develops into a small sac that covers the dorsal surface of the growing embryo. The roof of this cavity is formed by amniogenic cells derived from the trophoblast, while its floor is formed by the ectoderm. As the amnion enlarges it gradually engulf's the growing embryo which prolapses into its cavity. Distension of the amniotic sac eventually brings it into contact with the interior of the chorion, resulting in obliteration of the extra embryonic coelom. Further expansion of the amniotic cavity occurs at the expense of the uterine cavity. Gradually, the decidua capsularis fuses with the decidua parietalis and the uterine cavity is also obliterated. Still further expansion of the amniotic cavity is achieved by enlargement of the uterus. 
At the time of parturition the fused amnion and chorion (along with the greatly thinned out decidua capsularis) constitute what are called membranes.

Amnion:

The amnion is the inner of the two fetal membranes and as such, is in contact with the contents of the amniotic sac, namely the amniotic fluid and the fetus, The chorionic membrane is adjacent to the outer surface of the amniotic membrane, and separates the amnion from the decidua. This part of the amnion is called as placental amnion, while the remainder is referred to as the reflected amnion. A third area that directly overlies the internal cervical os is known as dependent amnion.

Amniotic membrane is not simply an epithelial lining for the uterine cavity but a well differentiated tissue.

There are five layers which from within outwards as follows:

1. Epithelium: Composed of a single layer of cuboidal cells. Recent research has implicated that the amniotic epithelium helps in the exchange of fluid and electrolytes that is not known to occur between the amniotic sac and the mother.

2. Basement Membrane It is a narrow band of reticular tissue lying along the base of the epithelial cells to which it is securely adherent. It is normally well defined over both the placental and reflected parts of the amnion.

3. Compact layer: A relatively dense, acellular layer and is composed of randomly scattered reticular fibrils, lying immediately deep to the basement membrane to which it is densely adherent.

4. Fibroblast layer: It is composed of a fibroblast network set in a mesh of eticulum. The only cells normally present are fibroblast and Hofbauer cells. It forms a considerable part of the thickness of the amnion.

5. Spongy layer : Composed of many collagenous bundles and it is capable of great distension and is responsible for permitting the amnion a surprising degree of movement upon the underlying fixed chorion.

The normal amnion is $0.02-0.5 \mathrm{~mm}$ in thickness. It varies greatly in thickness as a result of alteration in the mucin and fluid content.

It was unable to find blood vessels or nerves in the amnion at any stage of development and despite the occurrence of suggestive. Spaces in the fibroblastic and spongy layers could not identify distinct lymphatic channels $^{18}$.

\section{Chorion:}

The chorion being the outer of the two human fetal membranes, is in contact with the amnion on its inner aspect and the maternal decidua on its outer aspect.

The portion of the chorion overlying the placenta is called placental chorion, remainder is called reflected chorion and the portion overlying the internal os of the cervix is known as the dependent chorion.

The chorion is made up of 4 different layers on histological examination. They are from with in outwards as follows;

1. Cellular layer: This is a narrow layer consisting almost entirely of an interlacing fibroblast network similar to that present in the fibroblast layer of the amion.

2. Reticular layer: This layer forms the major part of the reticular tissue of chorion. It is made up of a network of reticulum in which fibroblasts and Hofbauer cells are embedded.

3. Basement membrane: This layer is a narrow band of reticular tissue -forming the basement membrane of the trophoblast which lies upon its deeper surface. The name pseudobasement membrane is used to avoid confusion with the basement membrane of the amnion.

4. Trophoblast: This is a layer of trophoblast cells about 4-6 cells in thickness, but is extremely variable, ranging from 0.04 to $0.40 \mathrm{~mm}$. Syncitio trophoblastic tissue is not normally visible in the reflected chorion at term, although it is present earlier in pregnancy. In some areas the chorion is healthy and functionally active. In other areas there is evidence of cellular degeneration and pyknosis of cell nuclei.

There is no evidence to show that the chorion at term has a capillary blood supply for its own nutrition. In early pregnancy the chorion leave possesses actively functioning chorionic villi.

There is a complex system of vessels through out the reticular layer of the entire chorion. As pregnancy advances the villi of the chorion frondosurn develop into the placenta and simultaneously the villi of the chorionic leave atrophy. The blood vessels supplying these atrophic viii also degenerate, but whereas villi persist with in the trophoblast layer of the chorion as atopic or ghost villi, the vessels altogether disappear.

But the reticular layer and the trophoblast contain relatively large spaces which demonstrable- content when studied by light microscopy, but actual endothelial lined lymphatic channels have not been observed. 


\section{Physiology Of Fetal Membranes:}

Fetal membranes contain an organization of enzymes requiring both synthesis and degradation of prostaglandins using specific methods ${ }^{19}$.

Chorioamnion serve as the site of storage and ultimately release of the prostaglandin precursor, arachidonic acid. The human membranes contain the enzyme phospholipase A2 which catalyses the hydrolysis of the glycerophospholipids leading to release of free arachidonic acid. So, fetal membranes have the capacity to provide the obligate precursor for the synthesis of PGE2 and PGF2 $\alpha$ while the contiguous uterine deciduas is known to contain prostaglandin synthetase system and occupy a central role in the initiation of human parturition. It was the ability of the placental villous tissue, membranes, umbilical cord, fetal skin, myometrium and decidua to metabolise exogenous prostaglandins ${ }^{19}$. The enzyme regulating the degradation of prostaglandins are distributed throughout the pregnant uterus. The highest activity of the metabolising enzymes is formed in the chorion and placenta. These structures also display an ability to synthesize prostaglandins in vitro.

The chorion could be the major source of endogenous intrauterine prostaglandins, since both the amnion and the decidua possess low potential for metabolizing prostaglandins, these substance could originate in the chorion and diffuse through the anmion into the amniotic fluid and through the deciduas into the myometrium without undergoing sizeable inactivation ${ }^{19}$. Prostaglandins facilitate myometrial contractions by inhibiting calcium sequestration in the sarcoplasmic reticulum.

Progesterone is essential for the establishment and maintenance of pregnancy in all the mammalian species. The withdrawal of progesterone is a pre-requisite for the onset of labour in humans.

The possibility exists that progesterone exerts a stabilizing effect in human fetal membranes which regulates the expression of the activity of phospholipase A2. The biochemical events leading to the onset of uterine contractions could be triggered by local progesterone and has many of the physical and chemical characteristics of transcortin which appears to be associated with the human fetal membranes largely after 37 weeks gestation. This binding of progesterone allows for the lysozymal enzyme activation. It has also been suggested that the ratio of estradiol and progesterone rather than their absolute concentration, may be more significant. Changes in the ratio locally in the fetal membranes and the decidua, may bring, about the changes in the sensitivity and excitability of myometrium at term to start the labour.

The chorioamnion also possess extensive enzymatic capabilities for steroid hormone metabolism including 5-alpha reductase, 3-13 hydroxyl steroid dehvdrogenase, D5-4 isomerase, $20 \alpha$ steroid-oxido reductase, 17 beta-dehydrogenase and other enzyme activities.

\section{Physical Properties Of Fetal Membranes:}

Evidence indicates that pre-term membranes are stronger than term membranes and indeed PROM occurs in $10 \%$ of pregnancies at term while in only $0.7-2 \%$ of pregnancies before 37 completed weeks. The relative rarity of pre-term PROM has prompted investigators to examine the physical properties of the foetal membranes in order to determine whether rupture is caused by an inherent weakness of the membrane material or by local defects in the membrane structure.

The chorioamniotic membranes exhibit physical properties characteristic of viscoelastic material. After a stress (eg. Contraction, fetal movement) the membranes exhibit deformation characteristics of both elastic and viscous materials simultaneously. With recovery, only the elastic component which has memory will return to its original state. Thus, less than the total deformation is recovered. The viscous component of the membranes might be influenced by the chemical constitution of the amniotic fluid with resultant changes in fluid osmolarity. The elastic component could be influenced by changes in the collagen network.

In the majority of pregnancies the fetal membranes ruptures spontaneously at term during the active phase of labour. Since a pressure of 56-58 $\mathrm{mm}$ of water is enough to rupture normal membranes over a circle of $10 \mathrm{~cm}$ diameter, this could explain membrane rupture at the end of first stage of labour. Since it requires much greater force to effect membrane rupture over a smaller, diameter, in order to explain pre-term premature rupture of membranes in the presence of an undilated cervix, it must be assumed that the membranes are pathologically altered in some manner at the site of rupture, regardless of their condition else where in the uterine cavity.

Early studies demonstrated that although the amnion is generally one third as thick as the chorion, it is five times as strong in its ability to withstand stress. However, the combined membranes are stronger since the chorion contributes a significant portion of tensile strength. Chorion is three quarters as defective as amnion in developing the tensile force. These initial studies consistently failed to demonstrate difference between prematurely and non-prematurely ruptured membranes in either rupture tension or initial resting membrane thickness. Infact, the bursting pressure of membranes from patients with pre-mature PROM was significantly higher than that of term membranes (Polishuk et al 1964). Sine the membranes generally were not evaluated at the actual site of rupture these results suggested that the local defect might be responsible for pre-mature PROM. 
During the course of labour the contraction during which spontaneous rupture of membranes occurred was not the strongest one to which the membranes were subject in $86 \%$ of the cases raised the possibility that membranes subject to repeated stresses were altered, becoming more brittle and heterogenous. There was definite histologic changes in the membranes following repetitive stretching in the form of loss of amniotic surface epithelium, splitting and breaking down of the compact layer, and separation of the amnion from the spongy layer.

The chorioamniotic membranes are subjected to multiple stresses during pregnancy. There is normal chronic stress resulting from physiologic expansion accompanying growth of the fetus and accumulation of amniotic fluid, The membranes have been stretched to twice their resting surface area by the enlarging uterus. Braxton Hicks contractions are physiologically present throughout the pregnancy.

The thickness of are membranes was reduced near the rupture site. They speculated that this thinning might represent a local phenomenon secondary to chronic stress during gestation, which slowly produces membrane changes ${ }^{24}$.

In addition, the modulus of elasticity was reduced for prematurely ruptured membranes at both the site of the rupture and the periplacental area. This might be interpreted physiologically to suggest that for the same strain than non-prematurely ruptured membranes. Alternatively, prematurely ruptured membranes develop the same strain as non-prematurely ruptured membranes at lower stress.

Where pressure is applied to the membranes the resultant stretched extension consists of 2 components, an elastic component that is recoverable and a non- recoverable component called the creep extension. After any deformation, the membrane will become thinner than it was Original as a function of the non- recoverable creep extension. Any biological material such as the chorioamnion will contain in homogenetics that present an applied stress from acting uniformly over its entire extent. Preterm membranes can sustain greater stress application than term membranes because of less strain hardening and a greater ability to creep allowing membranes to thin out more before rupturing.

The mechanical stress is induced by friction and adhesive forces that inhibit movement of chorion against the amnion or deciduas and prevent dissipation of locally applied forces arising from fetal movements. Amniotic fluid proteins such a albumin and globulin are good adhesive and might predispose to this situation. On the contrary, surface active phospholipids (surfactants), present in the amniotic fluid can adhere to the membranes making them hydrophobic, and decreasing their surface energy, thus improving their release and boundary lubricating properties. The data indicate that the surface energy of the chorion and amnion in cases of PROM is significantly higher than the, membranes that do not rupture prematurity. These membranes do not possess the properties necessary to avoid the build up of local mechanical stress and protect them from tear.

\section{Amniotic Fluid:}

The fetus is surrounded by amniotic fluid. The terms 'liquor amnii' and amniotic fluid, both imply a relation between the membrane and the fluid, beyond mere anatomical containment, and many have believed the membranes to be the origin of the amniotic fluid and the regulator of its water and solute content.

Thus composition of the amniotic fluid is different, in the two halves of pregnancy. In the first half, the concentration of the major solutes are more closely related to those in the fetal than in the maternal serum, and the amniotic fluid may be regarded as part of the fetal extracellular fluid space.

Sodium and water have been shown to pass through the fetal skin until the time the skin becomes impermeable, probably at about 20 week when the close relation between the fetal weight and the amniotic fluid volume breaks down.

In the second half of pregnancy, the biochemical composition of the amniotic fluid changes progressively as pregnancy advances, it may be that increasing stratification and cornification of the fetal skin impedes and finally prevents diffusion. Thereafter, the changing characteristics may reflect the maturation of the fetal renal function, explaining the rise in urea and creatinine concentrations and fall in osmolarity and sodium concentration.

The sources of origin of amniotic fluid are as follows;

1. Transudation from maternal blood across the membranes.

2. Fetal contributions

3. Transudation across skin, lungs, and umbilical cord.

4. Secretions from tracheo-bronchial tree genitourinary tract and oropharynx.

5. Secretions from amniotic epithelium

The volume of amniotic fluid increases rapidly with the growth of the products of conception averaging about $50 \mathrm{ml}$ at 12 weeks of pregnancy. At 20 weeks the volume is about $400 \mathrm{ml}$, at 35 weeks, it reaches a peak 
of nearly one liter. During the last few weeks of pregnancy its volume decreases and at 43 weeks the range varies from 100 to $600 \mathrm{ml}$.

\section{Composition Of Amniotic Fluid:}

The amniotic fluid is a heterogenous solution suspension. It consist of $98-99 \%$ water, $1-2 \%$ solids, about one half of the solids are organic, of this $50 \%$ is protein. Other organic constituents are glucose, urea, NPN, uric acid and creatinine.

\section{Electrolytes:}

During the first half of the pregnancy, sodium and chloride concentrations are more similar to fetal than maternal serum. Later, the fluid becomes progressively hypotonic with decreasing sodium and chloride values.

Potassium calcium, magnesium, phosphorus, zinc, iron and sulphur are also present with no significant changes as pregnancy advances. The mean level of bound zinc in amniotic fluid is 3.1 micro mole/l. Low amniotic fluid zinc level are associated with increased risk of infection.

\section{Hormones}

Various hormones present in the amniotic fluid include pregnanediol, oestriol 17-keta steroids and human prolactin.

\section{Enzymes:}

Alkaline phosphatase increases until 7th month of pregnancy and then remains constant. The concentration of acid phosphates is similar to that of the maternal serum. Other enzymes like monoamine lysozome have been identified in the amniotic fluid.

Prostaglandins have also been identified in the amniotic fluid. It has been shown that about $4 \%$ of water is exchanged per hour in the amniotic fluid. At term, the exchange from maternal to amniotic fluid is very small or negligible while the transfer rate from the fetus to the mother are high, being maximum from the fetus to the amniotic fluid. A considerable amount of amniotic fluid is lost by swallowing at the rate of $700 \mathrm{ml} / 24 \mathrm{hrs}$ by the fetus.

\section{Etiology Of Prom:}

In most pregnancies, labour begins in the presence of intact fetal membranes. Without intervention the membranes usually remain intact until approximately $8 \mathrm{~cm}$ of cervical dilation. The pressure necessary to cause membrane rupture experimentally not only is greater than the baseline resting tone of the intrauterine cavity, but also generally exceeds that generated by normal labour. The clinical entity of PROM that can occur in the absence of labour with an undilated cervix even at bed rest and also remote from term is an enigma that remains only imperfectly explained. Hence, a number of hypothesis have been proposed in an attempt to explain its etiology. At present, majority of instances of PROM probably are secondary to multiple factors ${ }^{16}$.

\section{Etiology Of Prom Has Been Related To Many Variables Including. \\ i. Maternal age \\ ii. Parity \\ iii. Trauma}

II. Presenting part acts like a ball valve, preventing the intrauterine pressure acting directly on the bag of membranes. Badly fitting presenting part as in malpresentations and cephalopelvic disproportion result in the intrauterine pressure being directly transmitted to the bag of membranes, causing it to rupture prematurely.

III. A number of pregnancy related conditions have been implicated in the etiology of PROM in individual instances. Multiple gestation and polyhydramnios have been noted, presumably acting by stretching the membranes excessively ${ }^{20}$. Other factors include placenta previa andpre-eclampsia ${ }^{4}$.

IV. Anatomic variations of the membranes such as marginal cord insertion might constitute a local defect, reducing tolerance to stress at that site. A 47\% incidence of PROM in association with this condition.

V. It was the inherent weakness of the membranes that is responsible for $\mathrm{PROM}^{21,24}$. Congenital and acquired fenestrations of membranes have also been implicated as causative factors.

VI. It has also been speculated that viral infection may involve the membranes with secondary rupture ${ }^{18}$. 
VII. Degeneration of amniotic epithelial cells is considered as a cause for premature rupture of membranes at term $^{18}$. Electron microscopy has revealed extensive degenerative changes in amniotic epithelial cells. It has been reported that plasminogen is fixed to damage amniotic epithelial cells and this may have a role in PROM especially in pre-term cases. Subsequent activation of the plasminogen to the powerful protease plasmin may be responsible for cellular damage leading to PROM.

VIII. The occurrence of a congenital defect in the amniotic membranes appearing as a small semilunar communication between the amniotic cavity and the space between amnion and chorion, situated near the insertion of the cord, which allows amniotic fluid to pass from the amniotic cavity to this space, where it leaks directly above the internal os.

IX. Variable thickness and tensile strength of the membranes have been reported as etiological factors.

$\mathbf{X}$. The strength of foetal membranes was inversely proportional to the fetal weight i.e., tensile strength was reduced with increased fetal weight. It is possible to postulate that the higher fetal weight may be responsible for the higher intrauterine pressure. This in turn is most likely to result in rupture of membranes with or without other underlying causes ${ }^{13}$.

XI. The dilated cervix in patients with cervical incompetence exposes the fetal membranes directly to the vaginal microflora and secretions, predisposing to both chorioamnionitis and PROM. Rupture of membranes in patients with an incompetent cervix is also frequently the inadvertent consequence of attempts to manage this condition by placement of a cervical encerclage ${ }^{22}$. Prostaglandins implicated as playing a role in post encirclage PROM.

XII. Ripening of cervix (the connective tissue of which, like the amnion, contains large amounts of collagen) and weakening of the amniotic membrane may be modulated by similar mechanisms that decrease the collagen content of these structures. The collagen content of the amnion decreased significantly during the last 8 weeks of pregnancy. In addition, the collagen content of amnion obtained from patients with PROM was significantly lower than that of amnion from patient without PROM, even after controlling for gestational age.

Reduction in collagen content in preterm amnion that rupture ${ }^{23}$. However, this reduction was not due to a general decrease of all collagen types but rather to specific and remarkable reduction in type III collagen, type III collagen is interstitial collagen with in the extra cellular matrix and is responsible for the elastic tenslity of the tissue. No difference in collagen types was observed at term whether or not PROM occurred.

XIII. The granulocyte elastase is capable of preferentially degrading Type III collagen. Any condition resulting in a neutrophilic infiltration of the amnion, such as infection might cause PROM.

XIV. Enzymes present in chorioamnion or amniotic fluid could depolymerase collagen by destroying the collagen cross link area $^{24}$. Since microorganisms present in the cervico-vaginal flora also produce proteases, exposure of the membranes to the genital tract microflora could cause local membrane weakening and PROM. Significant reduction in strain to rupture, work to rupture and rupture/ tension values of fetal membranes produced by incubating membranes for 24 hours in pseudo amniotic fluid could be prevented by addition of protease inhibitors to the incubation media.

$\mathbf{X V}$. Alterations in collagen would affect the elastic properties of the membranes while changes in the fluid osmolarity might affect its viscous component. Amniotic fluid prolactin appears to play a role in regulating the volume, osmolarity and electrolyte concentration of amniotic fluid and might therefore influence the viscoelastic properties of the fetal membranes ${ }^{22}$.

XVI. It is also possible that proteolytic enzymes from bacteria, and the inflammatory response they elicit in the host, might so weaken the membranes that PROM occur. The effect of Group B streptococcal infection on the amnion in the form of decrease in desmosome counts and alterations of the basement membrane ${ }^{25}$.

XVII. The membranes collected from patient with PROM following labour have significantly higher peroxidase activity ${ }^{26}$. Peroxidase in conjunction with hydrogen peroxide produced by bacteria and a halide constitute a potent antimicrobial system that is not only cytotoxic but capable of oxidatively cleaving peptide bonds and thus causing membrane weakness. These investigators also reported that treatment of fetal membranes with lysolecithin reduces their bursting pressure. Amniotic fluid contains lecithin, which can be converted to 
lysolecithin by the action of phospholipase A2. Therefore in the presence of bacterial contamination of the membranes these two mechanisms might act in concert to cause PROM.

It has been suggested that occult intra-uterine or ascending choriodecidual bacterial invasion in some instances precedes PROM. The thought that mild or moderate uterine activity may be brought about by subclinical Infection is supported by the finding of phospholipase A2 activity in vaginal flora bacteria (Eg. Bfragilis, peptostreptococcus species). This activity is postulated to trigger labour through prostaglandin synthesis from native amniotic membrane phospholipids. The contractions thus produced could cause early membrane rupture, especially if they have been subjected to stress over a prolonged period.

XVIII. The sequence of events is therefore thought to be infection, occult labour, membrane weakening, and then PROM. An alternate pathway for the initiation of uterine activity (and thus PROM) by infection process is as follows

Bacterial lipopoly saccharides (Endotoxin) in high concentration and interleukin-1 (Pyrogn) are apparently both capable of inducting production of PGE2 by amniotic epithelium, thus serving as signals for initiation of labour in presence of maternal or intramniotic infection.

XIX. A study of fetal immunoglobulin is associated with PROM. The cord IgA and IgM level was significantly elevated compared with levels in control infants ${ }^{27}$. More important, there was both clinical and immunological evidence (elevated IgA) of two distinct peaks of infection. The first occurred within 12 hours of rupture, while the other not until 12 hours of rupture, suggesting that for patient in the first group infection was present before rupture and might have been the cause of rupture.

XX. When compared cervical cultures from women having PROM with cultures from a control group of women, results showed that anaerobes, especially B. fragilis was present in women with PROM.

XXI. A significantly increased incidence of cervical colonization with C.trachomatis among patients with PROM as compared with a control population ${ }^{22}$.

XXII. Defects in the membranes may arise secondary to poor nutritional status or ingestion of toxic substances. Ascorbic acid is required for the production and maintenance of collagen in tissues. A relationship was found between low plasma ascorbic acid levels and PROM in patients from lower socio-economic classes.

XXIII. Copper plays an important role in the maturation of collagen and elastin, and it has been shown that copper deficient diet will result in increased fragility of supporting structures ${ }^{24}$.

XXIV. Zinc is a requisite constituent of the amniotic fluid zinc-polypeptide complex bacterial inhibitor in amniotic fluid Zinc deficiency might result in failure of the bacterial inhibitor to present intraamniotic infection and hence, PROM.

XXV. Sexual inter-course: Theoretically could initiate PROM by means of several mechanisms.

i. Bacteria in seminal fluid or vaginal secretion may be deposited adjacent to the cervical os and thus in proximity to the membranes.

ii. Uterine contractions stimulated by orgasm or the action of seminal prostaglandins can lead to premature labour.

iii. Seminal fluid enzymes could have a direct toxic effect on membranes ${ }^{22}$.

The relationship between coitus and chorioamnionitis was established. There was an increased incidence of chorioamnionitis limited to the extra placental membranes. The rupture of the membranes before the onset of labour was increased two fold in those patients with recent coitus.

XXVI. Alpha-I antitrypsin is a serine protease inhibitor. It decrease at term and is deficient in some disease states. In gestations complicated by preterm PROM compared with gestational age controls without ruptured membranes, amniotic fluid trypsin levels were elevated, where as $\alpha$-I antitrypsin levels were decreased. This recognized paradoxic shift in the ratio of amniotic fluid to trypsin- $\alpha$-antitrypsin levels.

The type-III collagen is the major component contributing to the elasticity and strength of the amnion. Collagenase activity obviously plays an important role in predisposing to rupture of membranes. In addition to trypsin and collagenase, there are several other collagenolytic enzymes, including neutrophil elastase, metallo proteases, gelatinase and proteoglyans and cystine proteinases such as lathepsin B collagenolytic which degrade the telopeptide ends and collagen, are important initiators of collagenolytic enzymes like trypsin and the cystine 
proteinases are controlled by regulatory inhibitors. With the normal progress of labour, the activity of those regulatory inhibitors diminish allowing a greater degree of collagenolytic activity.

XXVII. Smoking causes premature rupture of membranes:

Cigarette smoke extract inhibited the platelet activating factor acetyl hydrolase secretion by these cells. (both decidual macrophages and peripheral blood monocytes and macrophages). The inhibitory effect of cigarette smoke extract on the secretion was a hundred times more potent compared with its direct effect on the plasma enzyme. Glutathione and dithiotheriotol blocked the inhibition, where as catalse or superoxide dismutase did not. Nicotine and nicotinine have no effect on the secretion.

In a certain number of cases PROM has an iatrogenic etiology. In addition to rupture at the time of cervical encirclage, membranes may be ruptured inadvertently at the time of amniocentesis even when performed under sonographic guidance. Following second trimester amniocentesis for genetic evaluation and prenatal diagnosis, PROM occurs in less than $0.2 \%$ cases.

\section{Diagnosis}

In obstetric practice, cases often present before the onset of labor. with leaking membrane. In some cases it is easy to diagnose ruptured membranes by a vaginal examination when liquor is seen coming out or the presenting part is felt without the covering membrane. But in some cases it is not easy if the os is closed or when it is open and the bag of membrane is present with the possibility of a small, rent in the membrane is higher.

Diagnosis of ruptured membrane can be established clinically or by laboratory methods. Most often the diagnosis is obvious by history of leak and direct demonstration of leaking through cervical os carefully performed per speculum examination.

\section{History:}

History of sudden passage of fluid from vagina in a gravid patient is strongly suggestive of ruptured membrane, occasionally a single bolus of fluid has been passed without further leakage or intermittent leakage of fluid has been noted. These patients frequently have a so called second rupture of the membrane during labor as do those with fluids accumulation between amnion and chorion.

\section{Visualization Of Amniotic Fluid In The Vagina:}

A sterile speculum is introduced into the vagina and observe for amniotic fluid flowing from the cervix; copious fluid pouring out of the speculum is pathognomonic of rupture of membranes. Amniotic fluid is colourless and may contain white flecks (vernix). If no fluid is immediately seen, ask the patient to cough and observe for a gush of fluid per vagina or applying slight fundal pressure over the uterus may provoke leaking.

\section{Laboratory Diagnosis:}

In clinical practice many times pregnant women present with the history of watery vaginal discharge and physical examination may not reveal the diagnosis of PROM. This is particularly so when cervical os is closed or flat membrane felt over the presenting part on account of high leak. Other discharges like urine, excessive vaginal discharge and inflammatory exudates may also obscure the clinical diagnosis. In such conditions laboratory diagnosis helps. They are:

\section{Nitrazine Test:}

The vaginal PH is normally 4.5-5.5. Amniotic fluid, usually has a pH of 7-7.5. Nitrazine paper quickly will turn deep blue if the vaginal fluid has an alkaline $\mathrm{pH}$. The membranes probably are intact if the color of the paper remains yellow or changes to olive yellow. Antiseptic solutions, urine, blood and vaginal infections alter the vaginal $\mathrm{pH}$ and cause false positive result. This test is simple, rapid, inexpensive and fairly reliable method. The nitrazine test produce $12.7 \%$ false negative and $16.2 \%$ false positive results ${ }^{32}$.

\section{Fern Test:}

Ferning results from the drying out of salts contained in the amniotic fluid. The ferning is due to crystallization of sodium chloride derived from the amniotic fluid. To perform the test, a sample of fluid is placed on a glass slide and allowed to dry. The preparation is observed under microscope, looking for a crystallization pattern that resembles a fern, The accuracy of the test is affected by blood or meconium, the test may produce false positive results if the sample is obtained from the cervix, because dry cervical mucus forms an arborization pattern that may be confused with PROM. The fern test gives $4.8 \%$ false negative and $4.4 \%$ false positive results ${ }^{33}$. The diagnosis of PROM is close to $100 \%$ reliable if the vaginal fluid gives both positive nitrazine and positive fern test. 


\section{Evaporation Test: \\ Ultrasound Examination:}

USG should not be used as the primary means of diagnosis of PROM. False positive findings may occur in patients with oligohydramnios resulting from causes other than PROM, and false negative results may occur in patients with discrete amniotic fluid losses. However it should be assumed that PROM has occurred if ultrasound examination shows little or no fluid in the uterus. In contrast, the presence of a normal amount of fluid makes the diagnosis of PROM unlikely.

\section{Intra-Amniotic Fluorescein:}

Injection of fluorescein into the amniotic cavity is rarely indicated for the diagnosis of PROM. This procedure may be performed when PROM cannot be confirmed with non invasive technique. In these cases $1 \mathrm{ml}$ of sterile solution of $5 \%$ sodium fluorescein is injected into the amniotic cavity. A tampon is placed in the vagina and examined with a long wave, ultraviolet light 1 or 2 hours later. The detection of fluorescent material is equivalent to a positive diagnosis of PROM, one $\mathrm{ml}$ of sterile indigo carmine may be used instead of fluorescein and the tampon is inspected for the presence of a blue discolouration.

\section{Amnioscopy:}

Amnioscopy is an invasive procedure rarely indicated in the diagnosis or management of PROM. It requires a dispensible cervix to introduce a metallic or plastic cone for direct visualization of the membranes and the AF. Amnioscopy may cause PROM in patients with intact membranes and may carry a large bacterial inoculation into the amniotic cavity in patients with PROM.

\section{Diamine Oxidase Test:}

Diamine oxidase is an enzyme produced by decidua, which diffuses into the amniotic fluid, measurement of diamine oxidase by paper strips placed in contact with the vagina is an accurate way to diagnose PROM. The test requires relatively elaborate laboratory procedure and is not ready for general use.

\section{Fetal Fibronectin:}

Fetal fibronectin is a large molecular weight glycoprotein present in large amounts in the amniotic fluid. This substance can be detected in the endocervix or the vagina of patients with PROM by means of an enzyme linked immuosorbent assay. The test seems to be highly accurate and is not affected by blood, but meconium may interfere.

\section{Alpha Fetoprotein Test (AFP):}

AFP is present in high concentration in AF, but does not exist in vaginal secretions or in the urine. Therefore determination of this substance in the vaginal secretion is an accurate test for the diagnosis of PROM. A study using a rapid calorimetric monoclonal antibody AFP test found a sensitivity of $98 \%$ for AEP, $77 \%$ for nitrazine and $62 \%$ for ferning. Specificity was $100 \%$ for AFP test. Maternal blood contamination affects the accuracy of test.

\section{Identification Of Lanugo:}

This is a microscopy technique for detecting rupture of fetal membranes. Lanugo and uric acid crystals in vaginal fluid can be identified. The findings of fetal hair was specific, yet the process was time consuming, requiring preparation of multiple slides. Fetal hair was present in scanty quantity and identification of mate crystals was non specific. Because of these difficulties, the technique was abandoned.

\section{Staining For Lipid:}

Nile blue sulfate staining was introduced for the identification of desquamated fetal epithelial cells. Oxazone present in nile blue sulfate stains, the fetal cells orange brown ${ }^{34}$.

\section{Complications Of Prom}

Maternal Complications:

1) Chorioamnionitis:

Infection occurs frequently in patients with PROM. The early diagnosis and prompt treatment are essential. The overall evidence of chorioamnionitis ranges from $4.2 \% 10.5 \%$.

The diagnosis of chorioamnionitis is clinical. It requires the presence of fever $38^{\circ} \mathrm{C}$ and atleast 2 of the following conditions - Maternal tachycardia, fetal tachycardia, uterine tenderness, foul smelling amniotic fluid; maternal leukocytosis.

Amniotic fluid cultures are valuable for identifying the bacteria causing infection and their antibiotic sensitivity. The amniotic cavity generally is sterile. The term microbial invasion of the amniotic cavity refers to 
the presence of a positive amniotic fluid for microorganisms cultures, regardless of the presence or absence of clinical signs or symptoms of infection.

Pathologic chorioamnionitis refers to the presence of acute inflammatory lesions in placenta and membranes, varying degrees of polymorphonuclear leukocytic infiltration of the chorioamnion is found more frequently than the clinical disease.

The determination of C-reactive protein (CRP) in blood a substance that increases markedly in patients with infection. The median CRP concentration during pregnancy ranges from 0.7 to $0.9 \mathrm{mg} / \mathrm{dI}$.

The gram stain of $\mathrm{AF}$ is valuable for confirming the diagnosis of amnionitis.

Another valuable AF test is the leukocyte estrase assay. A positive assay has a $91 \%$ sensitivity and 95\% positive predictive value for the diagnosis of chorioamnionitis.

The incidence of chorioamnionitis infection is more if the latent perod is more than 24 hours. $1.7 \%$ of his patients developed fever within 24 hours after PROM, 7.5\% between 24-48 hours and 8.6\% beyond 48 hours ${ }^{10}$.

The patients may have endometritis, parameteritis, pyelonephritis. In rare cases of extensive infection with uterine necrosis multiple abscess or clostridial infection, a life saving hysterectomy may be necessary. Occasionally uncontrolled infection may lead to septicemia, shock, DIC and adult RDS and maternal death.

Unless the patient is grossly neglected maternal mortality should not occur due to PROM.

Maternal mortality and morbidity are primarily related to sepsis and complications arising from efforts to affect delivery such as oxytocin induction or caesarean section.

\section{2) Abruptio Placenta:}

Patients with PROM have an incidence of abruption placenta approximately 6\%. Abruptio usually occurs within the setting of prolonged and severe oligohydroamnios. Nelson et al in a retrospective analysis of all patients with prolonged PROM, estimated the risk of abruption during expectant management to be $4 \%$. The reason for the high incidence of abruption in patients with PROM is the progressive decrease in intrauterine surface area causing detachment of the placenta.

\section{3) Cord Prolapse}

If it is associated with malpresentation

\section{4) Dry Labor}

It continuous escape of liquid for long duration

\section{Fetal And Neonatal Complications:}

\section{1) Neonatal Sepsis:}

PROM increases the risk of infection in the neonate to around $1.3 \%$ following prolonged rupture of membrane and $8.7 \%$ of neonatal sepsis following prolonged rupture of membrane and $8.7 \%$ of neonatal sepsis following prolonged and clinical amnionitis. Significant predictive risk factors were histologic evidence of inflammation in the placental chorionic plate, gestational age less than 34 weeks, male sex, apgar score of less than 6 in 5 minutes and clinical amnionitis. Perinatal mortality is due to sepsis and respiratory distress. In recent study of PROM, the neonatal mortality was reported as $6.7 \%$ of which $55 \%$ was due to infection. Volume of AF remaining after PROM is of importance as it possess antibacterial activity. Neonatal infection may manifest as septicemia, meningitis pneumonia, pyoderma, umbilical sepsis and conjunctivitis.

The first manifestation of impending fetal infection are non reactive NST and the absence of fetal breathing movements.

The overall incidence of a perinatal mortality reported in the literature ranges from 2.6 to $11 \%$. According to Hassan et $\mathrm{al}^{35}$ incidence of neonatal mortality is $4.6 \%$

\section{2) Neonatal Rds:}

Gluck et $\mathrm{al}^{36}$ (1973) explained the acceleration of pulmonary maturity documenting following observations 1) PROM of more than 24 hours duration with a more matute $\mathrm{L} / \mathrm{s}$ ratio of amniotic fluid than normally expected for gestation 2) phosphatidyl glycerol apprared in the amniotic fluid at earlier period in gestation following PROM. 3) tracheal or pharyngeal aspirates from preterm infants following PROM of more than 24 hours showed a mature phospholipid pattern at gestation ranging from 29 to 33 weeks. Jones reviewed 16000 births and concluded that there was no association between decreased incidence of RDS and prolongation of latent period after PROM. Aktar et $\mathrm{al}^{29}$ reported $11.1 \%$ of incidence of RDS in study of PROM. 
Oligohydromnia:

When PROM is managed conservatively, most patients have oligohydranmios to a greater or lesser degrees as a result of continuous leakage of amniotic fluid. Neonates delivered from pregnancies complicated by oligohydranmios sometimes have anomalies such as pulmonary hypoplasia or retarded growth or both ${ }^{37}$.

The absence of amniotic fluid allows the uterus to exert continuous pressure against the fetus resulting in abnormal fetal growth and development. Fetal breathing movements have been shown to be critical for normal lung development.

Increase in the incidence of caesarean section of fetal distress because of intrapartum fetal heart rate patterns consistent with umbilical cord compression. There is increased incidence of skeletal deformities due to pressure effect by oligohydramnios.

\section{Perinatal Mortality:}

The perinatal mortality rate is $10.1 \%$ according to collaborative perinatal study. Perinatal mortality after PROM near term ia associated with infection and in preterm due to RDS. Perinatal mortality is $19 \%$ according to Tanir et $\mathrm{al}^{38}$.

\section{Management Of Prom}

Two main approaches to the patient with PROM are conservative and aggressive.Aggresive approach is based on fear of infection consists of delivery within 24-48 hours of rupture of membrane.

Management depends on traditional age, Russel et $\mathrm{al}^{20}$ have shown that after 36 weeks of gestation $80 \%$ established labour within 24 hours whereas before 36 weeks only 50-70\% go in labour within 48 hours. They advocate an aggressive approach because of sepsis occurring after PROM.

Gun et $\mathrm{al}^{16}$ demonstrated and increased perinatal mortality rate after 48 hours of PROM and advocated an early delivery. While Cushner ${ }^{39}$ (1972) recommended expectant line of management unless there is sign of sepsis because according to him neonatal morbidity and mortality associated with PROM is due to prematurity and low birth weight.

A series of questions have to be answered

1. Are there signs and symptoms of intra uterine infections.

2. A positive answer to this indicates that management should be directed towards rapid termination of pregnancy. It also implies initiation of aggressive antibiotic therapy endocervical swabs for aerobic and anaerobic cultures taken.

If vaginal delivery is contraindicated loading dose of antibiotics is given at least 1 hour before caesarean. The aim of this dose is to obtain antibiotic tissue levels that present colonization and secondary spread.

If oxytocin fails to produce cervical changes and vaginal delivery is not in sight after 12 hours of induction, patient must be delivered by caesarean. If the answer to this question is negative then

\section{2) Is Mother At High Risk Of Developing Infection?}

A meticulous review of past and present medical history of mother is important. Whether patient is on drugs, has heart disease, diabetes, anaemia.if one of the above the termination of pregnancy. If answer to this is negative

\section{3) Is This An Abnormal Foetus?}

Carefull USG should be done in every case especially in pregnancy remote from term. If answer is positive terminate pregnancy.

If answer is negative, then the next question is

4) If Pregnancy 34 Weeks Of Gestation And Or Foetal Weight 2000 Gms?

For this estimation of gestational age is important (from LMP, early pelvic examination, history of quickening) USG should be done in case of doubt.

In case the answer is yes patient must be delivered. There is no good reason to expose the mother and fetus to risk of infection. In such cases if no sign of infection are present, one may wait for 24-48 hours after PROM before induction. Since $81 \%$ will start labour within 24 hours of PROM. If fetal weight is 2500 gms, $51 \%$ if weight is between $1000-2500$ gms.

If answer is no, then patient is candidate for expectant management.

\section{Objective Of Expectant Treatment}

1. in cases remote from term is to decrease perinatal mortality and morbidity. 
2. evidence suggesting that decreased incidence of RDS with prolongation of latent period.

Main risk is conservative treatment is risk of infection

\section{A) Gestation Between 30-34 Weeks}

Here approximate birth weight is $1200-2000$ gms. Hence a limited prolongation of latent period is required. So administration of tocolytics to stop labor is required for 24 hours. After this period tocolytics are withdrawn.

\section{B) Gestation 30 Weeks}

Fetus is still remote from lung maturation, they require tocolysis to accelerate lung maturation as well as pharmacologic intervention to accelerate lung maturation. Betamethasone is given 12 hours apart as $12 \mathrm{mg}$.

\section{Expectant Mamgament}

1. Obtain endocervical swabs

2. Start Cap.Ampicillin $250 \mathrm{mg}$ qid

3. Restrict patient to bed rest

4. Regular diet

5. Do not do manual pelvic examination

6. Monitor

a) maternal temptrature, pulse every 2 hours, fetal heart rate monitoring hourly

b) WBC count every 12 hours

c) check uterine tenderness, foul smelling liquor and amount of leak.

7. Evaluate use of tocolytics and should be discontinued after 24 hours of PROM

8. Administer betamethasone in gestational age less than 34 weeks.

Use of steroids to mature fetal lungs is controversial as there is some evidence that suggests that PROM of itself may stimulate fetal maturity. A prospective and randomized study of the use of corticosteroids in the management of PROM and premature gestation done by Garite ${ }^{45}$ (1981) suggests that chorioamionitis, respiratory distress syndrome, perinatal deaths, neonatal infections, caesarean section rates, birth weights or gestational age when the steroid treatment group was compared with the placebo treated group. Maternal post partum endometritis among woman delivered vaginally was significantly higher for the steroid treated group. The frequency of prolonged hospital stay was significantly higher for neonates in the steroid group. If the infection occurs induction must be initiated.

Liggins and Howie ${ }^{40}$ made an extensive study on the results of administration of steroids to accelerate lung maturity. They observed that steroids administered to accelerate lung maturation in the preterm fetus. They also demonstrated a significant lowering of the incidence of RDS in infants born before 34 weeks of pregnancy, when steroids were administered at 24 hours prior to delivery.

The increase in fetal lung surfactant is transient and action remains for seven days. If the patient fails to deliver after more than 7 days of steroid therapy, treatment should be considered. Steroids however must not be used in case for PIH and diabetes. If concomitant maternal tocolysis is carried out pulmonary oedema might occur.

\section{Materials And Methods}

This is a prospective study carried out at Basaveshwar Teaching \& General Hospital and Sangameshwar Hospital, Gulbarga attached to M.R.Medical College, Gulbarga over a period from December 2009 to May 2011. 100 cases taken for study and 100 as controls.

Selection Of Cases: Cases Selected In The Study Had To Fulfill The Following Inclusion Criteria Inclusion Criteria:

- Gestaional age beyond 28 and $<37$ weeks.

- Primi gravida / Multi gravida

- Singleton / twin pregnancy

- Mal presentations

- Polyhydramnios

- Mother with diabetes mellitus

- $\mathrm{PIH} /$ preeclampsia

- Confirmation of PROM by a speculum examination 


\section{Exclusion Criteria:}

- $\quad$ PROM more than 37 weeks

- Congenital anomalies / IUD

\section{Procedure Of Study}

Number of cases: 100 study and 100 control

All the patients coming with history of premature rupture of membranes before onset of labor pains were admitted to labour room.

A detailed history was taken Age, parity, menstrual and obstetric history with emphasis on exact time of rupture, duration, amount of leaking and association of pain, history of previous similar episodes in other pregnancies and history suggestive of incompetent os were evaluated. Detailed history regarding recent coitus, severe physical exertion and vagina and examinations if any before admissions was noted.

In general examination pulse, BP and temperature were noted followed by systemic examination. In obstetric uterine height, presentation, position, lie of fetus and amount of liquor were noted. All parameters of maternal and fetal well being were recorded.

A sterile speculum examination was conducted and presence of liquor amni was noted. When frank leaking was present the liquor was sent for culture and sensitivity. When no amniotic fluid was seen in the vagina, patient was asked to cough and per speculum done to see the drainage of amniotic fluid. In case of doubt fluid from vagina was collected on slide and examined under microscope for ferning. A single pelvic examination was done to note the Bishop's Score presence or absence of membranes, presenting part and its station and to rule out cord prolapse and also pelvic assessment. All patients with leaking received prophylactic antibiotics in the form of $500 \mathrm{mg}$ Ampicillin $6^{\text {th }}$ hourly. Thereafter the patient was monitored $4^{\text {th }}$ hourly for signs of infections.

A $4^{\text {th }}$ hourly monitoring of pulse, BP, temperature and presence or absence of contractions was made whenever required. The same was carried out more frequently. Fetal heart sounds were recorded every $1 / 2$ hour initially.

\section{Results}

Table-1: Age wise distribution

\begin{tabular}{|c|c|c|}
\hline Age group & Study & Control \\
\hline$\leq 20$ & 22 & 27 \\
\hline $21-25$ & 49 & 54 \\
\hline $26-30$ & 25 & 15 \\
\hline$>30$ & 4 & 4 \\
\hline Total & 100 & 100 \\
\hline
\end{tabular}

Majority belong to $21-25$ with mean age of $23.0 \pm 3.5$ and $23.4 \pm 2.9$ in PROM patients and control groups. Pvalue statistically not significant.

Figure-1: Age wise distribution

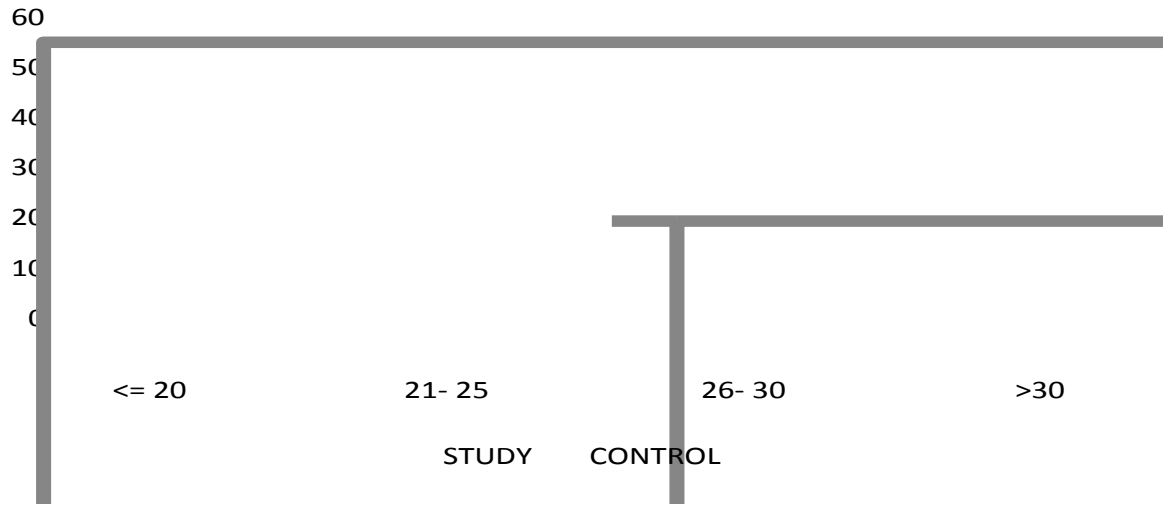

Table-2: Relational to Antenatal Care

\begin{tabular}{|c|c|c|}
\hline ANC & Study & Control \\
\hline Booked & 699 & 80 \\
\hline Unbooked & 31 & 20 \\
\hline Total & 100 & 100 \\
\hline
\end{tabular}

The above table shows that no significant correlation between antenatal care and incidence of PROM. 
Figure-2: Relational to Antenatal Care

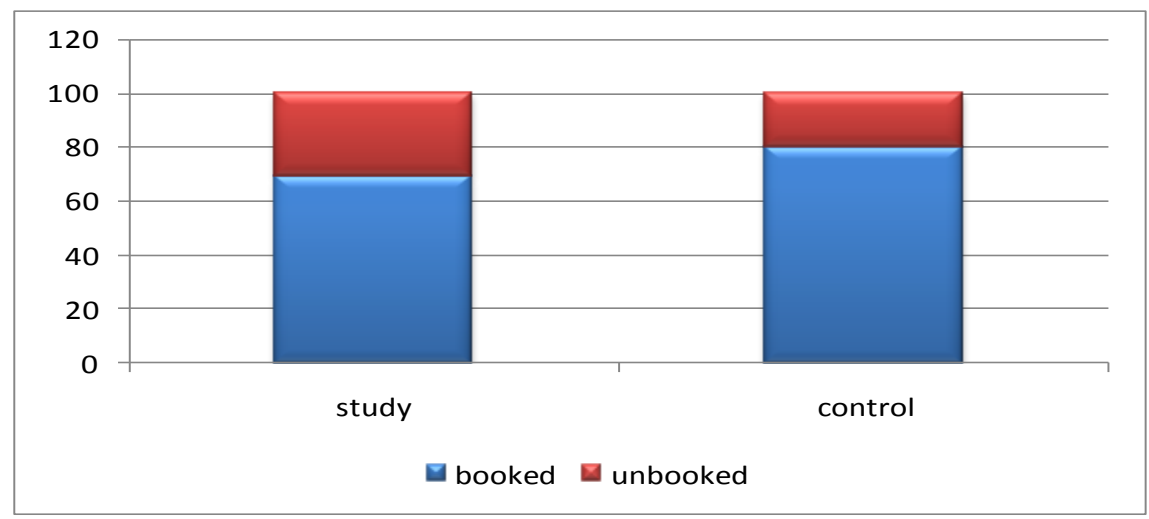

Table-3: Parity-Wise Distribution

\begin{tabular}{|c|c|c|}
\hline Parity & Study & Control \\
\hline Primi gravida & 53 & 52 \\
\hline Gravida-2 & 26 & 33 \\
\hline Gravida-3 & 14 & 12 \\
\hline$\geq \mathrm{G}-4$ & 07 & 03 \\
\hline Total & 100 & 100 \\
\hline
\end{tabular}

The above shows that PROM occurs more frequently in primigravida compared to that of multigravida.

Figure-3: Parity-Wise Distribution

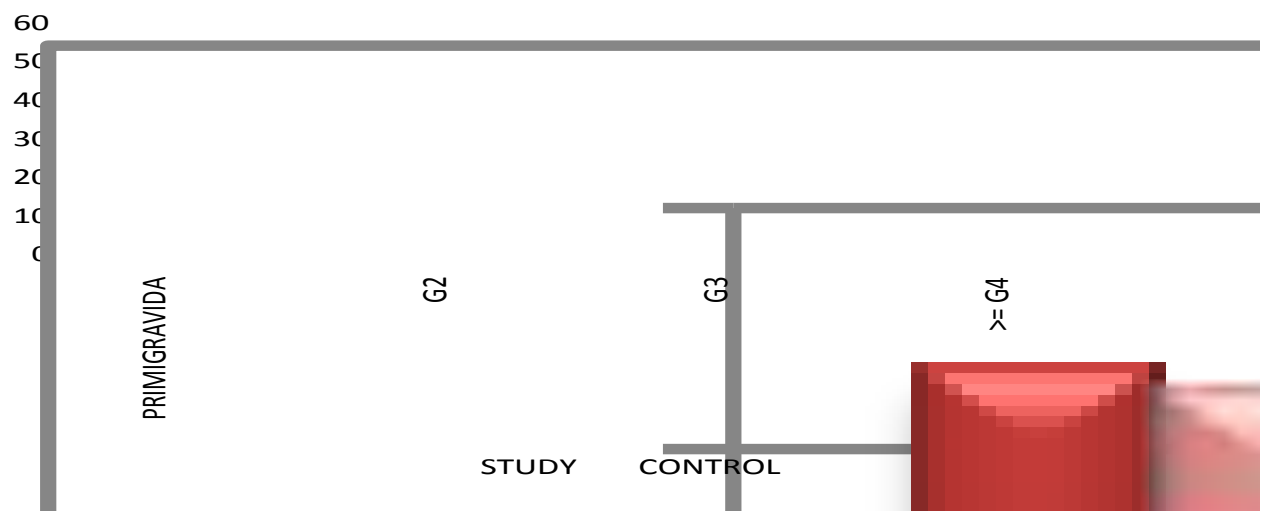

Table-4: Risk factors for PROM

\begin{tabular}{||l|c|c|}
\hline \multicolumn{1}{|c|}{ Risk factors } & Study & Control \\
\hline \hline Unknown & 59 & 00 \\
\hline Breech & 13 & 4 \\
\hline History of recent coitus & 10 & 0 \\
\hline Previous history of PROM & 6 & 1 \\
\hline Polyhydraminos & 4 & 1 \\
\hline Twins & 2 & 2 \\
\hline UTI & 6 & 2 \\
\hline
\end{tabular}

The above table shows risk factors in relation to PROM. It is evident that malpresentation $13 \%$ and history of coitus $10 \%$, UTI and previous history of PROM constitute to $6 \%$. P-value is highly significant. 
Figure-4: Risk factors for PROM

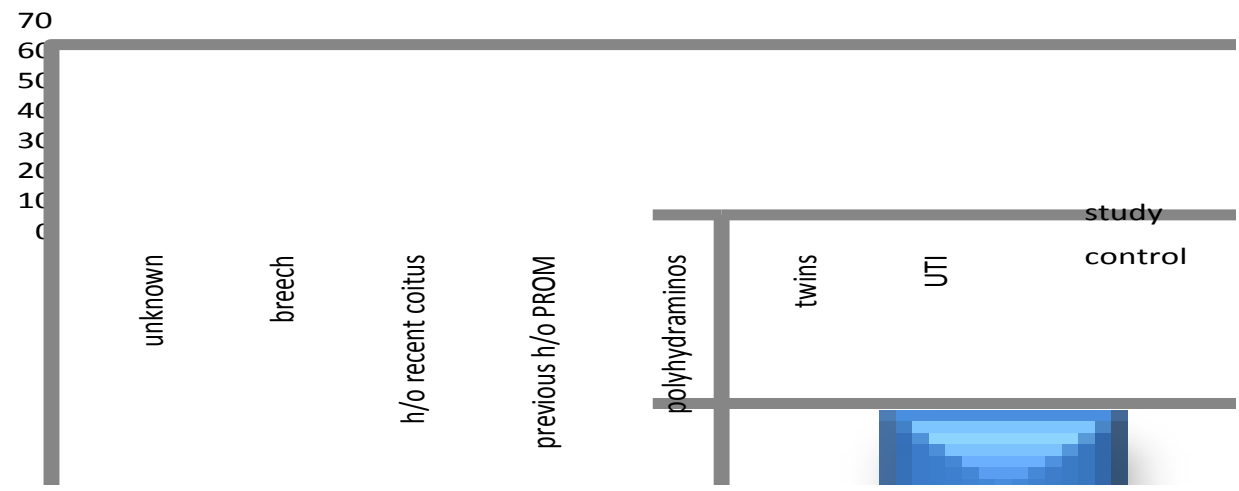

Figure-5: Risk factors for PROM in study group

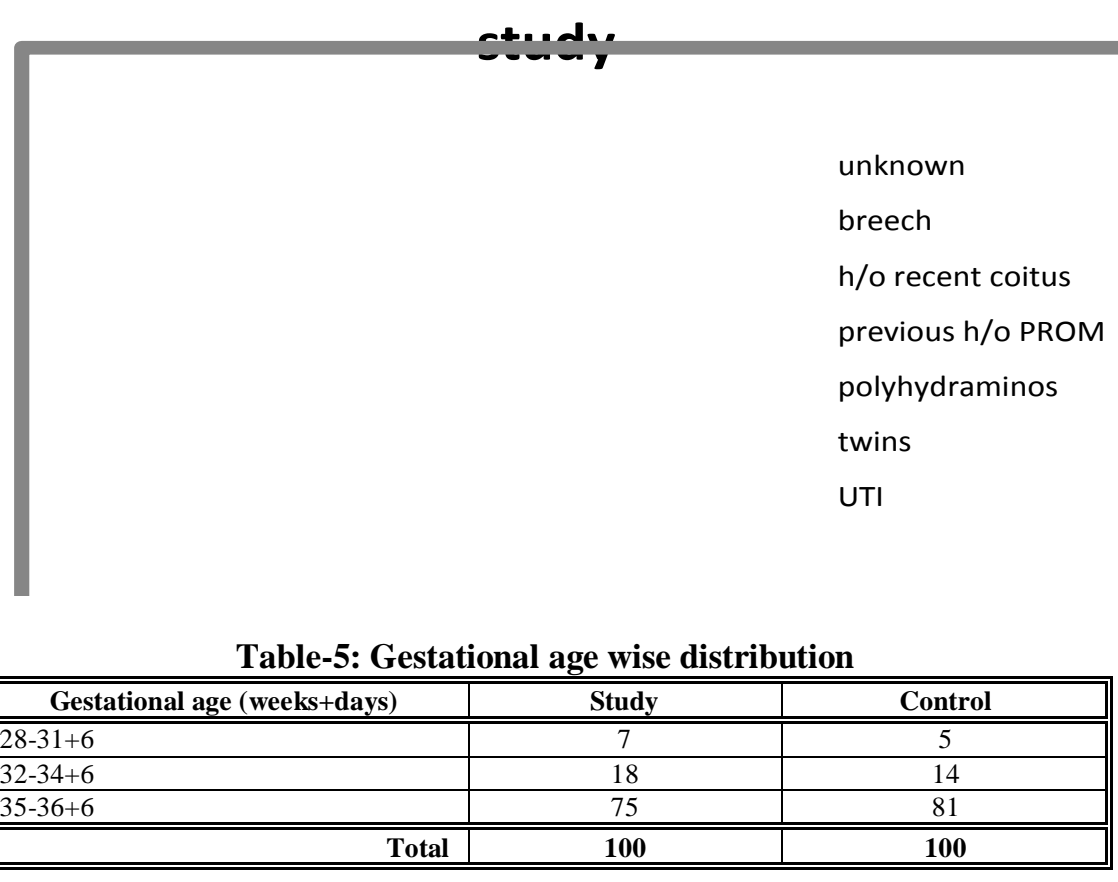

Out of 100 cases, percentage of PROM with gestational age <32 weeks corresponds to $7 \%$ and those near term corresponds to $75 \%$.

Figure-6: Gestational age wise distribution

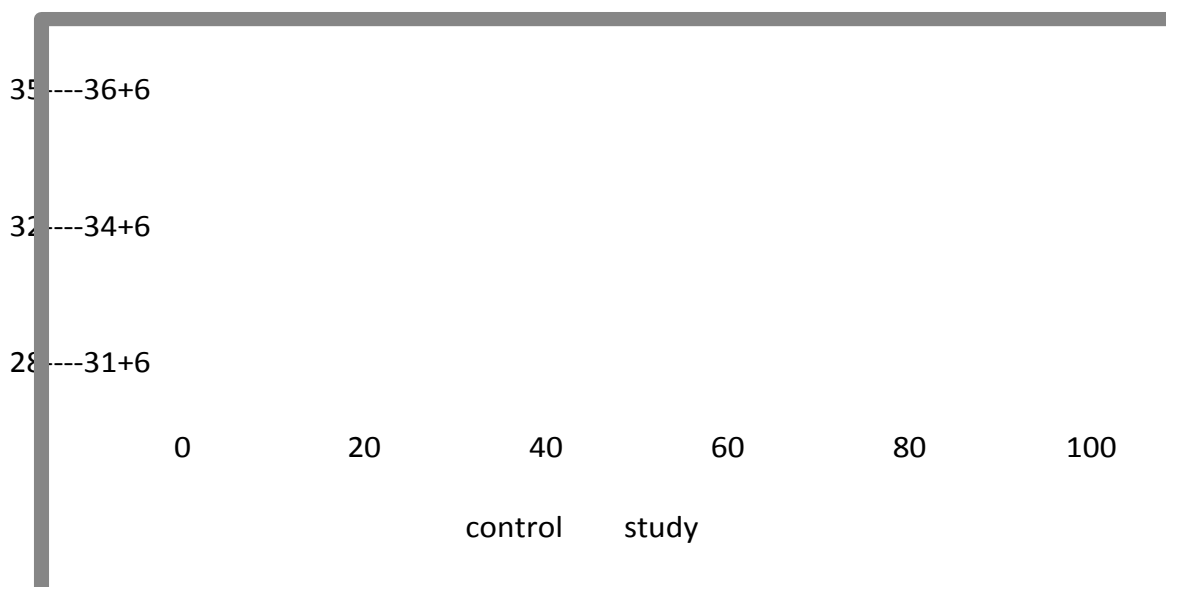


Table-6: Latent Period Wise Distribution Of Gestational Age

\begin{tabular}{|c|c|c|c|c|c|c|}
\hline \multirow{3}{*}{ Latent period (hours) } & \multicolumn{6}{|c|}{ Gestational age (weeks+days) } \\
\hline & \multicolumn{2}{|c|}{$28-31+6$} & \multicolumn{2}{|c|}{$32-34+6$} & \multicolumn{2}{|c|}{$35-36+6$} \\
\hline & No. & $\%$ & No. & $\%$ & No. & $\%$ \\
\hline $0-24$ & 1 & 14.28 & 6 & 33.33 & 57 & 76.00 \\
\hline $25-72$ & 4 & 57.14 & 10 & 55.55 & 16 & 21.33 \\
\hline$>72$ & 2 & 28.37 & 2 & 11.11 & 2 & 2.66 \\
\hline Total & 7 & 99.79 & 18 & 99.99 & 75 & 99.99 \\
\hline
\end{tabular}

Among 100 PROM cases studied as gestational age improves, latent period shortens. In the gestational period of 28-31+6, those crossing 72 hours are in significant percentage i.e., 28.37, while that between 32-34+6 are of $11.11 \%$ and only $2 \%$ of patients are between $35-36+6$ weeks of gestation who crossed 72 hours.

Figure-7: Latent Period Wise Distribution Of Gestational Age

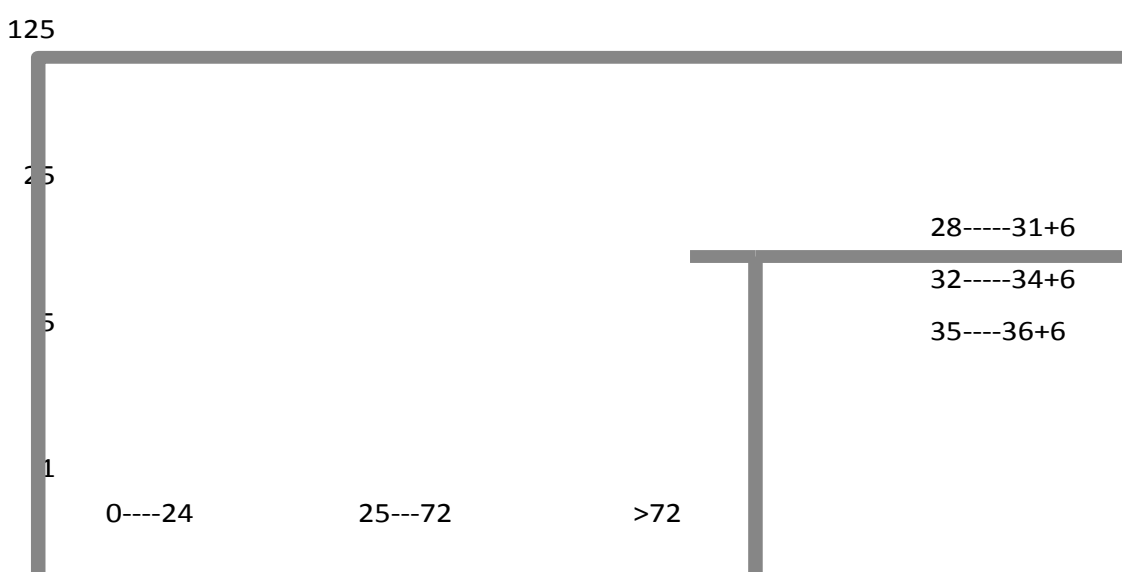

Table-7: Mode of delivery

\begin{tabular}{||l|c|c|}
\hline \multicolumn{1}{|c|}{ Mode of delivery } & Study & Control \\
\hline \hline Vaginal & 55 & 80 \\
\hline Breech (assisted) & 6 & 2 \\
\hline Twin (vaginal) & 2 & 4 \\
\hline Vacuum extraction & 10 & 6 \\
\hline LSCS & 27 & 8 \\
\hline \hline \multicolumn{1}{|c|}{ Total } & $\mathbf{1 0 0}$ & $\mathbf{1 0 0}$ \\
\hline
\end{tabular}

Incidence of LSCS and instrumental deliveries were found higher in PROM than in controls.

Figure-8: Mode of delivery

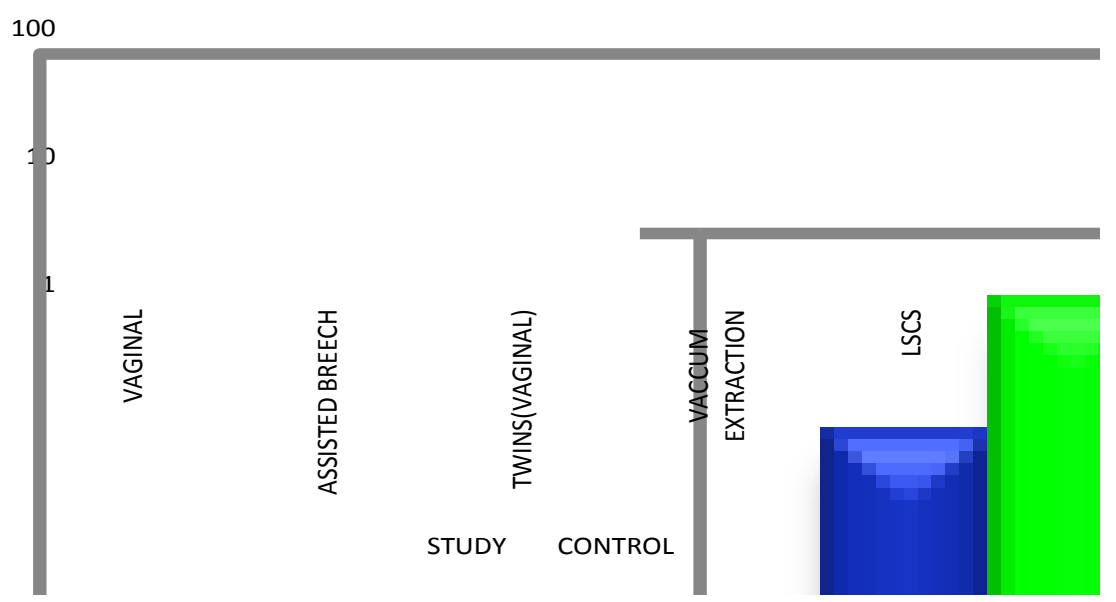




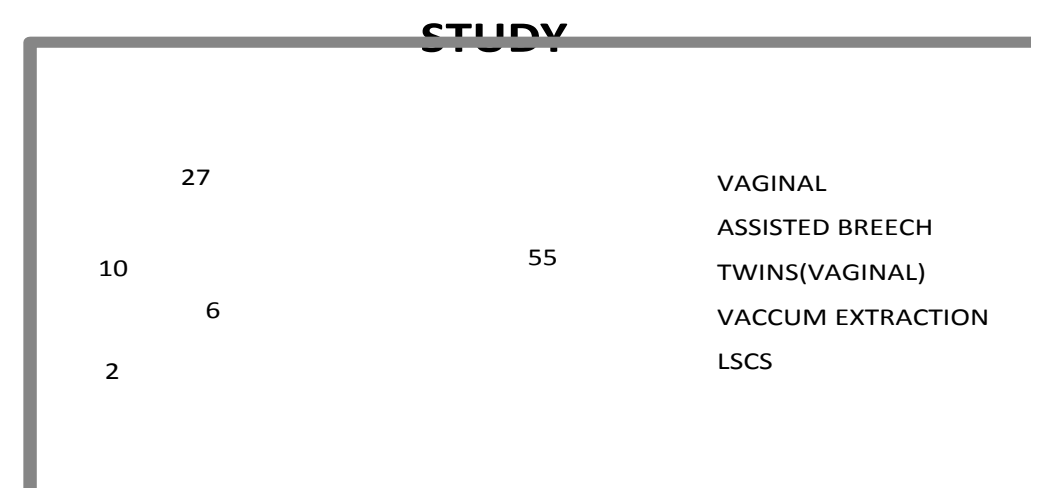

Table-8: Vaginal delivery (spontaneous versus induced)

\begin{tabular}{|c|c|c|}
\hline Mode of vaginal delivery & Number & Percentage \\
\hline Spontaneous vaginal & 60 & 82.19 \\
\hline Induced with cerviprime & 13 & 17.80 \\
\hline Total & 100 & 100 \\
\hline
\end{tabular}

Out of all vaginal deliveries, percentage of patients who had spontaneous labour were $82.19 \%$, while $17.8 \%$ were induced.

Table-9: Indications For LSCS In Study Group

\begin{tabular}{||l|c|c|}
\hline \multicolumn{1}{|c|}{ Indications } & No. & Percentage \\
\hline \hline Previous LSCS & 3 & 11.11 \\
\hline Breech & 6 & 22.22 \\
\hline Foetal distress & 14 & 51.85 \\
\hline CPD & 4 & 14.80 \\
\hline \hline & $\mathbf{2 7}$ & $\mathbf{1 0 0}$ \\
\hline
\end{tabular}

This table shows that the main indication for LSCS in this study is non reassuring fetal heart rate, which constitute to $51.85 \%$. The second most common indication is breech i.e., $22.22 \%$. Other indications include previous LSCS in $11.11 \%$ and CPD in $14.8 \%$.

Figure-9: Indications For LSCS In Study Group

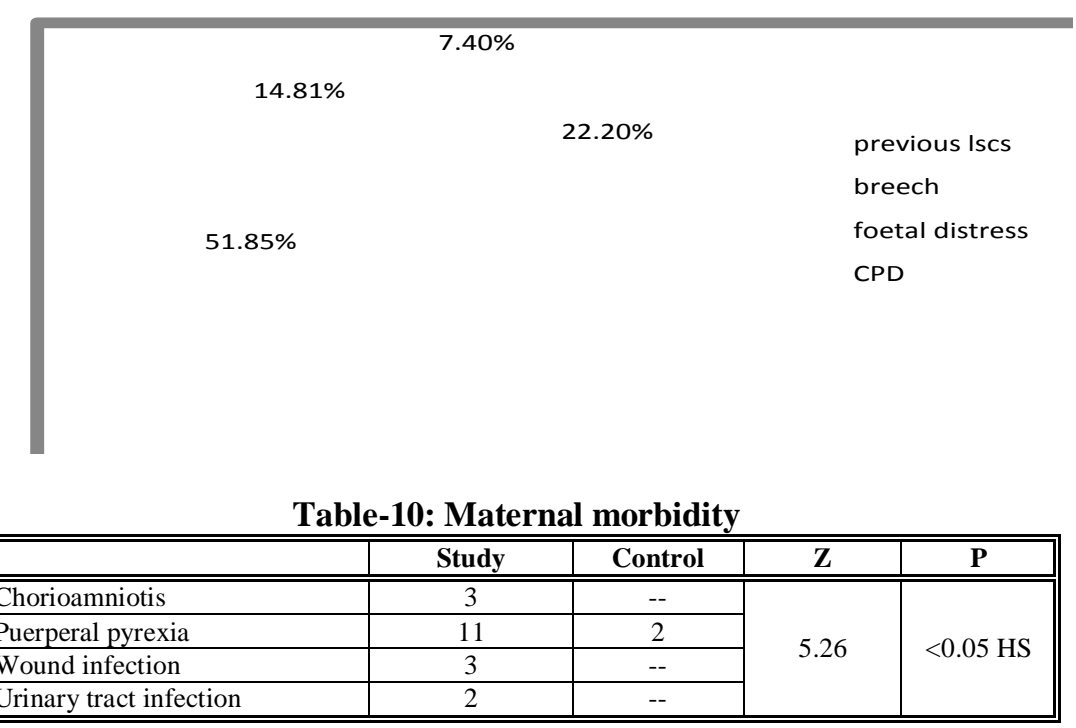

The above table shows that as compared to control group which showed $2 \%$ pyrexial fever, $11 \%$ had puerperal pyrexia with PROM, $3 \%$ chorioamniotis and $3 \%$ wound infection and $2 \%$ accounted to UTI. 


\section{Figure-10: Maternal morbidity}

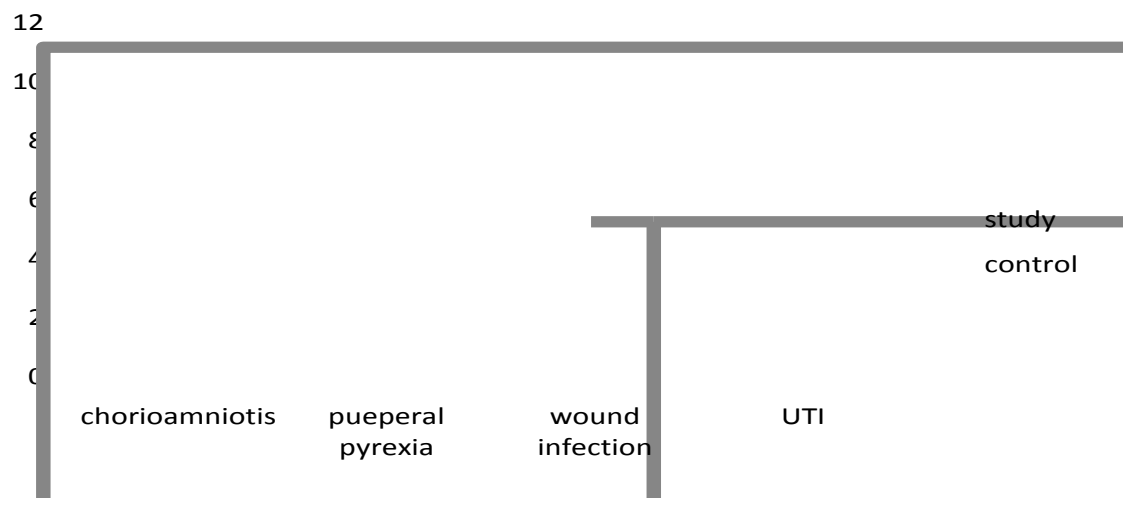

Table-11: Maternal morbidity in relation to latent period

\begin{tabular}{||l|c|c|c|}
\hline \multicolumn{1}{|c|}{ Latent period (hours) } & Peurperial fever & Chorioamniotis & Wound infection \\
\hline \hline 0-24 hours & 2 & 0 & 2 \\
\hline 25-72 hours & 5 & 1 & 1 \\
\hline
\end{tabular}

The above table shows that, puerperal fever and wound infection accounts to $3.125 \%$ in the latent period of 0-24 hours, while in latent period of 25-72 hours, puerperal fever accounts to $16.6 \%$ and wound infection $3.33 \%$ and $3.33 \%$ had chorioamniotis. In patients with latent period $>72$ hours, $66.6 \%$ had puerperal fever and chorioamniotis accounts to $33.33 \%$. In UCCA series, the overall prevalence of chorioamniotis irrespective of infant weight and gestational age was $2.7 \%$. $<12$ hours, $6.3 \%$ between $16-24$ hours and $16.4 \%$ after 24 hours.

Figure-11: Maternal morbidity in relation to latent period

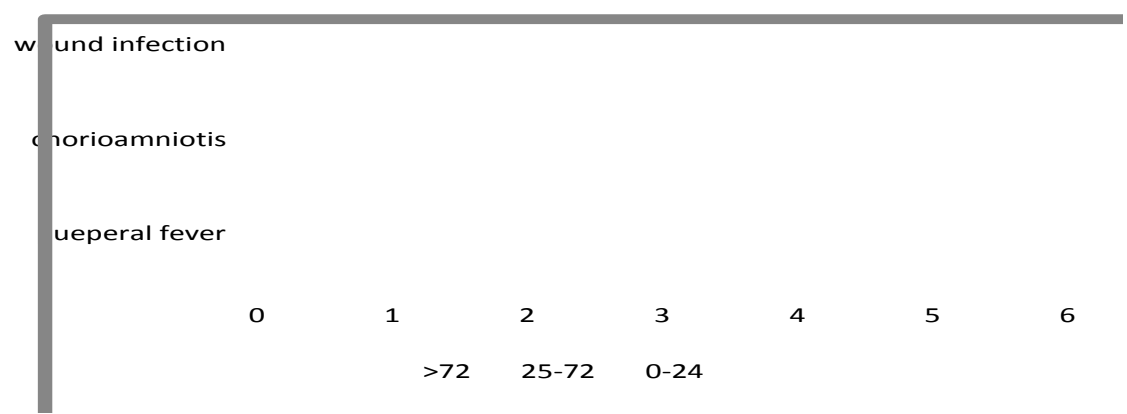

Table-12: Neonatal morbidity

\begin{tabular}{||l|c|c|c|c||}
\hline & Study & Control & $\boldsymbol{\chi}^{\mathbf{2}}$ & P \\
\hline \hline Respiratory distress syndrome & 26 & 12 & 6.37 & $<0.05$ \\
\hline Septicemia & 14 & -- & 12.98 & $>0.001$ \\
\hline Jaundice & 3 & 3 & 0.172 & $>0.05$ \\
\hline Conjunctivitis & 3 & -- & 1.35 & $>0.05$ \\
\hline Intraventricular hemorrhage & 4 & 2 & 0.12 & $>0.05$ \\
\hline
\end{tabular}

From the above table, it can be observed that out of 100 cases studies, $26 \%$ accounted for respiratory distress syndrome, while $12 \%$ in control group. $14 \%$ septicemia in study group. This proved to have a highly significant value, while conjunctivitis, neonatal jaundice (hyperbilirubinemia) and intraventricular hemorrhage accounted for $3 \%, 3 \%$ and $4 \%$ each. 
Figure-12: Neonatal morbidity

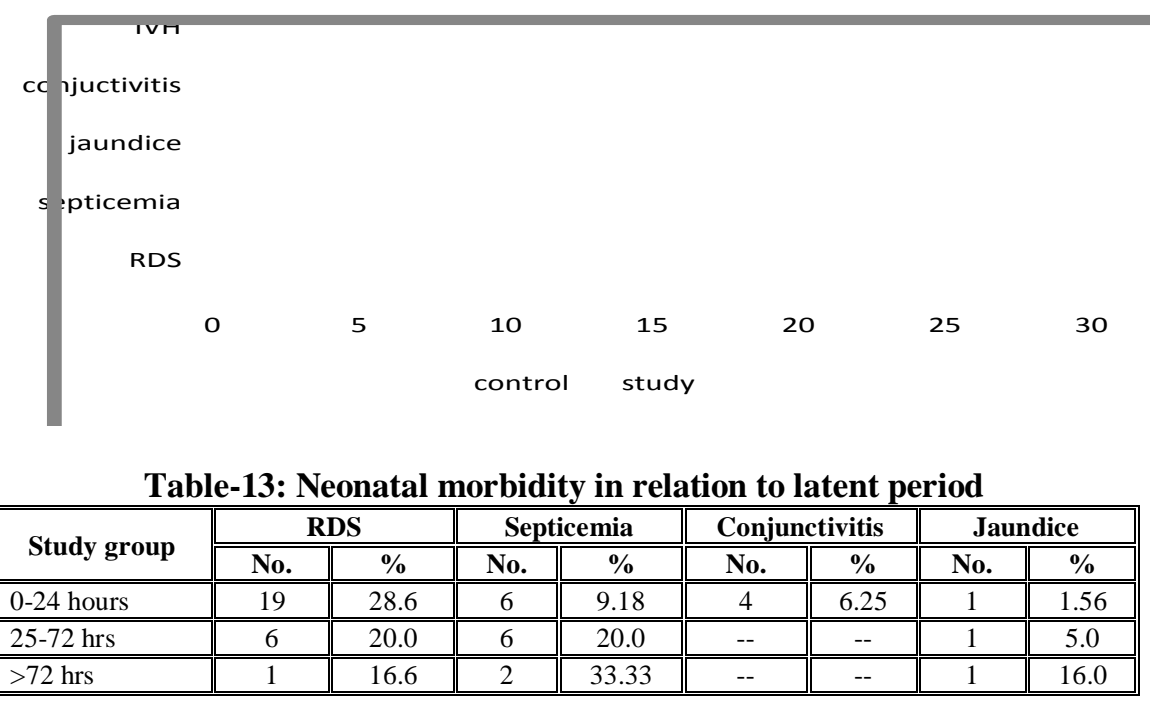

The above data shows that, with increase in the latent period, there is decrease in the respiratory distress syndrome, while increased rate of septicemia was observed in increased latent period.

\section{Figure-13: Neonatal Morbidity In Relation To Latent Period}

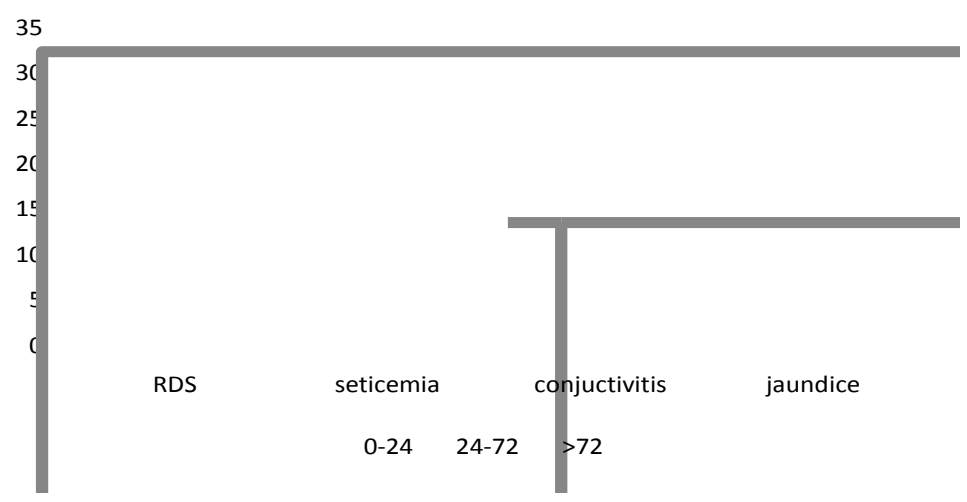

Table-14: NICU admission

\begin{tabular}{||l|c|c|c|c||}
\hline \multicolumn{1}{|c|}{ NICU admission } & $\mathbf{2 8 - 3 1 + 6}$ & $\mathbf{3 2 - 3 4 + 6}$ & $\mathbf{3 5 - 3 6 + 6}$ & Total \\
\hline \hline Study group & $6(85.7 \%)$ & $10(55.5 \%)$ & $19(25.5 \%$ & 36 \\
\hline Control & $4(80 \%)$ & $6(42.8 \%)$ & $8(9.8)$ & 18 \\
\hline
\end{tabular}

The above table shows that out of 100 cases each in the present study and control group, $36 \%$ in study group and $18 \%$ of controls had NICU admission, which is almost double and in between gestational age group of 35-36+6 gestation, it had highly significant value.

Figure-14: NICU admission

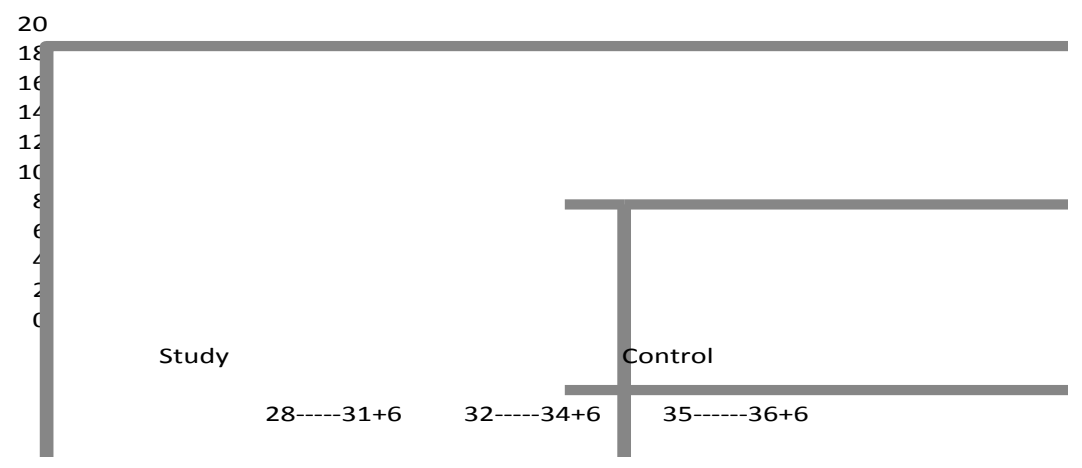


Table-15: Neonatal death

\begin{tabular}{|l|c|c|c|c|}
\hline \multicolumn{1}{|c|}{ Neonatal death } & $\mathbf{2 8 - 3 1 + 6}$ & $\mathbf{3 2 - 3 4 + 6}$ & $\mathbf{3 5 - 3 6 + 6}$ & Total \\
\hline \hline Study group & $2(28.8)$ & $4(22.2)$ & $1(1.33)$ & 7 \\
\hline Control & $1(20 \%)$ & $1(7 \%)$ & 00 & 2 \\
\hline
\end{tabular}

$\chi^{2}=6.221$ $\mathrm{p}<0.01$

According to this table, in study group $28.8 \%$ of neonatal death in between the gestational age of 28 $31+6$, while $20 \%$ in control group.

In the gestational period of $32-34+6$ weeks, $22.2 \%$ in study and $7 \%$ in control. P-value is highly significant while in the period of $35-36+6$, the neonatal death is $1.33 \%$.

\section{Figure-15: Neonatal Death}

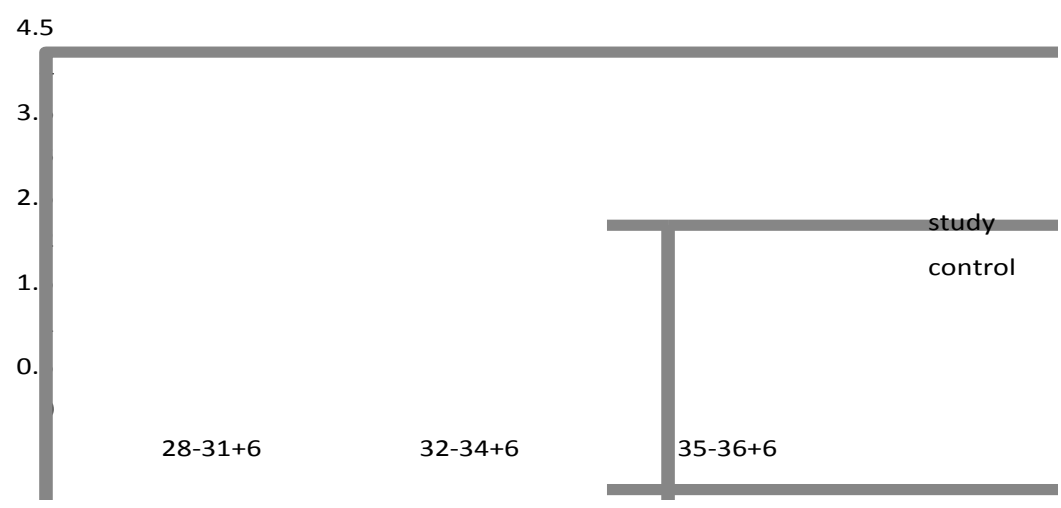

Table-16: Birth Weight Wise Distribution

\begin{tabular}{|c|c|c|}
\hline Birth weight (kgs) & Study & Control \\
\hline$<1.5$ & 15 & 10 \\
\hline $1.5-2.0$ & 16 & 20 \\
\hline $2.0-2.5$ & 37 & 38 \\
\hline$>2.5$ & 34 & 36 \\
\hline Total & 102 & 104 \\
\hline
\end{tabular}

The above data shows that there was no significant difference between study and control groups with respect to birth weight.

Figure-16: Birth Weight Wise Distribution

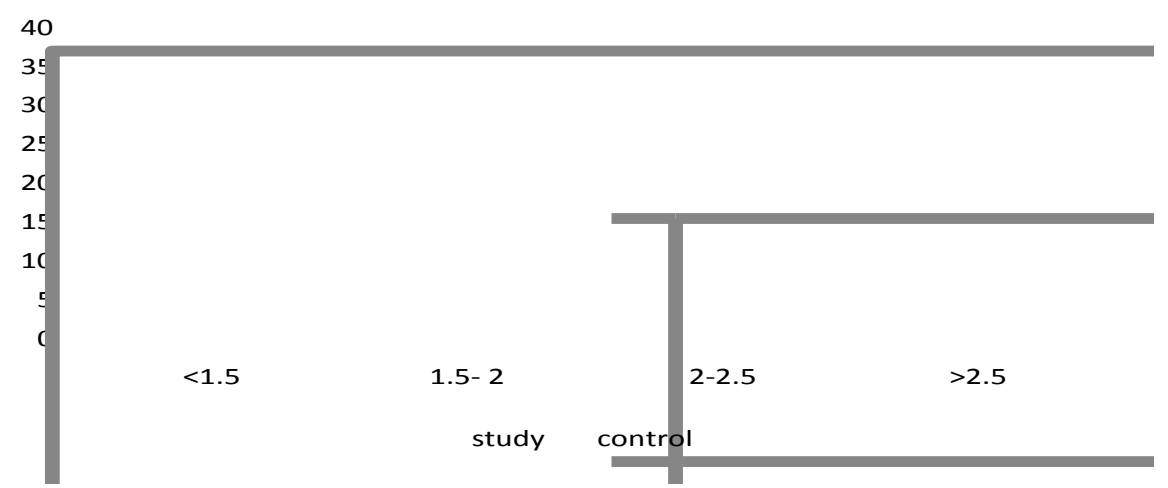

Table-17: Relationship Of Birth Weight With Neonatal Death In Study Group

\begin{tabular}{||l|c|c|c|}
\hline \multirow{2}{*}{ Birth weight (kgs) } & \multirow{2}{*}{ Total } & \multicolumn{2}{|c|}{ Neonatal death } \\
\cline { 3 - 4 } & & Number & Percent \\
\hline \hline$<1.5$ & 15 & 5 & 33.33 \\
\hline $1.5-2.0$ & 16 & 1 & 6.25 \\
\hline $2.0-2.5$ & 37 & 1 & 2.70 \\
\hline$>2.5$ & 34 & -- & -- \\
\hline
\end{tabular}

The above table shows that, significant number deaths were observed in babies with birth weight less than 1.5. 


\section{Figure-17: Relationship Of Birth Weight With Neonatal Death In Study Group}

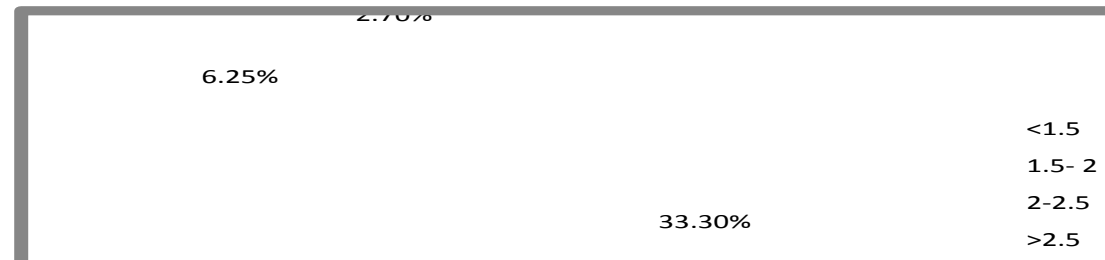

\section{Discussion}

Premature rupture of membranes is fairly a common complication of pregnancy and can lead to increased maternal complications, operative procedures, neonatal morbidity and mortality

The present study was undertaken to identify risk factors causing PROM and to study labor outcome maternal morbidity and perinatal morbidity and mortality associated with PROM

\section{Age Of The Patient}

For this study the cases were selected from all age groups . maternal age group between 21- 26 years was the most common age group. These findings correlated with study of Akter et al ${ }^{11}$ who found that $40.33 \%$ of 300 cases of PROM belong to age group between $21-25$ years. In our study $49 \%$ of Cases were grouped between to 21-25 yrs.

These findings also correlated with other study

\begin{tabular}{||l||c||}
\hline \hline & Mean age \\
\hline \hline Varner MW et $\mathrm{al}^{28}$ & 25 \\
\hline \hline Present study & $23.0 \pm 3.5$ \\
\hline
\end{tabular}

\section{Antenatal Care:}

$69 \%$ of cases with PROM are booked compared to $80 \%$ in control group. There was no significant correlation between the antenatal care and incidence of PROM.

Parity:

According to $\mathrm{Aktar}^{11}$ et al chances of increased sexual activity and increased genital infection are most common among primigravida. In this study $53 \%$ were primigravida compared to control group

\begin{tabular}{||l|c||}
\hline & $\begin{array}{c}\text { \% of } \\
\text { primigravida }\end{array}$ \\
\hline \hline Aktar ${ }^{11}$ et al study & $45 \%$ \\
\hline \hline S Akter $(2010)^{29}$ study & $38 \%$ \\
\hline \hline
\end{tabular}

\section{Risk Factors In Relation To PROM:}

In the current study most common known risk factors present in this study group were malpresentations $(13 \%)$ and $\mathrm{h} / \mathrm{o}$ recent coitus $(10 \%)$ and previous h/o PROM and UTI accounts for $6 \%$ each

In the study by Newton $\mathrm{ER}^{31}, 8 \%$ of patients gave h/o PROM during their previous pregnancy. They stated that genetic factors as well as possible vaginal/ cervical infection could be contributory factor.

Increased incidence of PROM in breech presentation has been noted according to Gunn et al study ${ }^{16}$.

\section{Gestational Age Wise Distribution:}

Out of 100 cases studied the percentage of PROM 28-31+6 weeks accounts to 7\%. That between $32-$ $34+6$ accounts for $18 \%$ and $75 \%$ between $35-36+6$ gestational age.

\begin{tabular}{|l|c|}
\hline & Incidence of preterm prom \\
\hline \hline Danforth $\mathrm{DN}^{37}$ study & $30 \%$ \\
\hline \hline Our study & $33.8 \%$ \\
\hline
\end{tabular}




\section{Latent Period:}

In the present study of gestational age with respect to latent period shows that, as gestational age increases, latent period shortens. Out of 100 cases with spontaneous rupture of membranes $64 \%$ cases went into labor within 24 hours, while 30\% cases went into labor after $25-72$ hours. $6 \%$ of cases had prolonged rupture of membranes i.e., more than 72 hours.

According to Russels ${ }^{20} 80 \%$ establish labor in 24 hours

\section{Mode Of Delivery:}

Out of 100 cases $73 \%$ had vaginal deliveries $27 \%$ patients had LSCS. In our study of PROM cases and Control group. Incidence of instrumental and LSCS is higher in PROM than controls.

$27 \%$ of patients underwent LSCS because various indications mainly being Foetal distress (51.85\%) and second most common indication is breech $(22.22 \%)$.

\begin{tabular}{||l||c||}
\hline & Caesarean rate \\
\hline \hline Shehla et al study & $14.0 \%$ \\
\hline \hline Tahir s et al study & ${ }^{42}$ \\
\hline \hline Chales PJ study & $20.0 \%$ \\
\hline \hline Present study & $58.7 \%$ \\
\hline \hline
\end{tabular}

Number of induced cases in this study was $17.8 \%$ while $82.19 \%$ went into spontaneous labour. Out of 13 patients induced with cerviprime, 1 was failed induction. Rate of caeserean section among patients with failed induction $11.8 \%$ according to Snehamay et $\mathrm{al}^{44}$ while in the study group failed induction $7.69 \%$.

\section{Maternal Morbidity:}

In our study $11 \%$ had puerperal fever in study group in comparison to control group which is $2 \%$. And incidence of chorioamnionitis is $3 \%$ in study group.

\begin{tabular}{|l||c||c|}
\hline \hline & Puerperal pyrexia & Chorioamnionitis \\
\hline \hline Artal k study ${ }^{24}$ & $13 \%$ & $3-13 \%$ \\
\hline \hline Our study & $11 \%$ & $3 \%$ \\
\hline \hline
\end{tabular}
after 48 hours.

Burchell study ${ }^{10}$ found that $1.7 \%$ of his patients developed fever within 24 hours of PROM, $18.6 \%$

In our study incidence of puerperal fever within 24 hours is $3.125 \%$ and between $24-72$ hours is $16.6 \%$ and after 72 hours puerperal fever is $66.6 \%$, while chorioamnionitis after 24 hours is $3.33 \%$ and $33.33 \%$ after 72 hours. Risk of chorioamnionitis is $20 \%$ between $28-34$ weeks ${ }^{46}$

\section{Neonatal Morbidity}

In our study of 100 cases, $26 \%$ of babies suffered from respiratory distress syndrome, $14 \%$ from septicemia and $3 \%$ from neonatal jaundice and conjunctivitis and $4 \%$ from intraventricular haemmorrahage.

\begin{tabular}{||l||c||c|}
\hline & RDS & Septicemia \\
\hline \hline Mark H. Yudnic et al $^{47}$ & $48.7 \%$ & $8.4 \%$ \\
\hline \hline S Akter et al ${ }^{29}$ & $11.1 \%$ & $6.7 \%$ \\
\hline \hline Nili \& Sham & $33.3 \%$ & $5.5 \%$ \\
\hline \hline Present study & $26 \%$ & $14 \%$ \\
\hline
\end{tabular}

Heuback $(1948)^{48}$ found that latent period is more important factor than gestational age for the risk of neonatal infection, similarly gestational age is more important factor for risk of RDS than latent period, in relation to latent period,

\begin{tabular}{|l||c|c|}
\hline \hline \multicolumn{1}{|c|}{ Septicemia } & Nili and Sham study & Present study \\
\hline \hline$<24$ hours & $18.4 \%$ & $20 \%$ \\
\hline \hline$>24$ hours-48 hours & $15.3 \%$ & $20 \%$ \\
\hline$>72$ & -- & $33.3 \%$ \\
\hline
\end{tabular}

\begin{tabular}{||l||c|c|}
\hline \multicolumn{1}{|c|}{ RDS } & Nili and sham study ${ }^{\mathbf{1 1}}$ & Present study \\
\hline \hline$<24$ hours & $33.7 \%$ & $28.6 \%$ \\
\hline \hline$>24$ hours- 48 hours & $33.3 \%$ & $20.0 \%$ \\
\hline \hline 72 hours & -- & $16.6 \%$ \\
\hline
\end{tabular}

In our case, there was one baby suffered from pneumonia in the mother who crossed the latent period of 72 hours. 


\begin{tabular}{||l||c|}
\hline & $\begin{array}{c}\text { Percentage of pneumonia in } \\
\text { PROM }\end{array}$ \\
\hline \hline Hassan Boskadi et $\mathrm{al}^{35}$ & $1.3 \%$ \\
\hline \hline Medina et al ${ }^{49}$ & $0.9 \%$ \\
\hline \hline Present study & $0.5 \%$ \\
\hline
\end{tabular}

\section{NICU Admission:}

In our study $36 \%$ of babies were admitted to NICU following PROM, out of this admission, < 35 weeks of gestation in our study is $64 \%$.

\begin{tabular}{||l||c|}
\hline & $\begin{array}{c}\text { NICU admission in< 35 } \\
\text { weeks }\end{array}$ \\
\hline \hline Hassan boskadi ${ }^{35}$ study & $65.3 \%$ \\
\hline \hline Tanir et $\mathrm{al}^{38}$ study & $75.0 \%$ \\
\hline \hline Present study & $64.0 \%$ \\
\hline
\end{tabular}

In the gestational age $<32$ weeks it is $85.7 \%$ and $>35$ weeks it is $25.5 \%$

\section{Neonatal Death:}

Severe asphyxia and sepsis and CNS haemorrhage were major cause of death in our infants.

\begin{tabular}{||l||c|}
\hline \hline & $\begin{array}{c}\text { Percentage of neonatal } \\
\text { death }\end{array}$ \\
\hline \hline Tavasseli et al ${ }^{50}$ & $8.8 \%$ \\
\hline \hline Hassan Boskadi et al ${ }^{35}$ & $4.6 \%$ \\
\hline \hline Present study & $7.0 \%$ \\
\hline
\end{tabular}

Neonatal death with respective to birth weight, $33.33 \%$ of neonatal death was attributed to birth weight $<1.5 \mathrm{~kg}$. $6.25 \%$ of death between (1.5- 2) $\mathrm{kg}$ and $2.7 \%$ between b. wt $(2-2.5) \mathrm{kg}$

\begin{tabular}{|l||c||c|}
\hline & Perkins $\mathbf{R P}^{52}$ study & Present study \\
\hline \hline$<1.5 \mathrm{~kg}$ & $31.07 \%$ & $33.3 \%$ \\
\hline \hline$>1.5 \mathrm{~kg}$ & $5.5 \%$ & $6.25 \%$ \\
\hline
\end{tabular}

Neonatal Death In Relation To Latent Period

\begin{tabular}{|c|c|c|}
\hline & Nili and Sham study $^{51}$ & Present study \\
\hline$<24$ & $7.6 \%$ & $1.56 \%$ \\
\hline$>24$ hours & $28.3 \%$ & $16.66 \%$ \\
\hline
\end{tabular}

In latent period of more than 24 hours the studies are comparable

\section{Conclusion}

Premature rupture of fetal chorioamniotic membranes by definition occurs before the onset of labor. Premature rupture of fetal membranes (PROM) occurs in a proximately $10 \%$ of all pregnancies. When this event occurs before 37 weeks of gestation, it is termed preterm premature rupture of membranes (PPROM) that has been estimated to affect $3 \%$ to $4.5 \%$ of all deliveries.

To conclude premature rupture of membranes is common cause of preterm delivery. Thus, it is responsible for increased perinatal morbidity and mortality. Though excellent advances in care of preterm babies may reduce the perinatal morbidity and mortality following PROM, the ultimate solution lies in accurate determination of etiological factors and prevention of rupture of membranes before term.

Antenatal diagnosis of preterm PROM by identifying risk factors is an important tool in the management of preterm PROM. Preterm prelabor rupture of membranes has significant impact on perinatal out come. But our main target was healthy mother and healthy baby. In managing PPROM, timely use of proper antibiotics, steroids and induction or augmentation of labor, reduce hospital stay and ultimately reduce perinatal and maternal complications.

The neonatal mortality of the newborns with a weight under $1500 \mathrm{~g}$ is significantly higher if the baby is born after prolonged PROM. Although prematurity and its associated problems, is the most common complication of PROM but the incidence rate of sepsis, asphyxia and RDS are also increased. 


\section{Summary}

To summarize the present study, it was conducted in Basaveshwar Teaching \& General Hospital and Sangameshwar Hospital attached to M.R.Medical College, Gulbarga. The study group constituted 100 women of more than 28 weeks and less than 37 weeks of gestation with confirmed PROM and 100 women without PROM are considered as control group.

- The objectives were to study the risk factors causing PROM, labour outcome and maternal and perinatal morbidity and mortality associated with PROM.

- In general examination pulse, BP and temperature were noted followed by systemic examination. In obstetric examination, uterine height, presentation, position, lie of foetus and amount of liquor were noted. All the maternal and fetal parameters were recorded.

- For the diagnosis of chorioamnionitis, maternal pulse, temperature, fetal tachycardia, uterine irritability and tenderness were used. All study cases received prophylactic antibiotic.

- Single pelvic examination was done to note the condition of cervix, present or absence of membrane, presenting part and its station. A $4^{\text {th }}$ hourly record of maternal pulse, BP, temperature and present or absence of contractions were noted. Labour was induced depending on the maternal or fetal interest.

- The variables were studied in each group separately and compared with controls.

- The present study shows that $53 \%$ of the patients were primi gravida with a mean age of $23 \pm 3.5$ years.

- The risk factors in the present were malpresentation in $13 \%$ and history of recent coitus in $10 \%$.

- The rate of caesarean section was $27 \%$ and $17.8 \%$ were induced among vaginal delivery.

- $11 \%$ of the patients had puerperal pyrexia and $3 \%$ suffered with chorioamnionitis.

- Higher incidence of respiratory distress syndrome was observed in $26 \%$ and septicemia in $14 \%$ was observed in the present study.

- $64 \%$ of babies with gestational age less than 35 had NICU admissions.

- In the present study, neonatal mortality was observed in 7\%, among which babies with birth weight less than $1.5 \mathrm{~kg}$, percentage of neonatal death was $33.3 \%$.

\section{Bibliography}

[1]. Gould GM \& Pyle WL. Anomalies and curiosities of medicine. New York, 1937. The Julian Press Inc as cited by Ekvall.

[2]. Delee AM, Joseph and Greenhill. In: Principle \& Practice of Obstetrics. WB Saunders Co., London, $1943: 666$.

[3]. Guise JM, Duff P, Christian JS. Management of term patients with premature rupture of membranes and an unfavourable cervix. Am J Perinatol 1992; 9: 56-60.

[4]. Natale R, Miline JK, Campbell MK, Pottis PG, Webster K, Halinda E. Management of premature rupture of menbranes at term randomized trial. Am J Obstet Gynecol 1994; 171(4): 936-9.

[5]. Jairam VK, Sudha S. A study of premature rupture of membranes - Management and Outcome. Journal of Obstet \& Gynec of India. 2001; 51(2): 58-60

[6]. Kenyon S, Boulvin M, Neilson J. Antibiotics for premature rupture of membranes: A systemic review. Obstet and Gynecol 2004; 104(5): 1051-7.

[7]. Stedman CM, Crawford S, Stalen E, Cherney WB. Management of premature rupture of membranes assessing amniotic fluid in the vagina for phosphatidyl glycerol. Am J Obstet Gynecol 1981; 140: 34.

[8]. Pritchard IA, McDonald PC. New York Appleton Century Craft, 1980

[9]. Mead PB. Management of the patient with premature rupture of membranes. Clinics Perinatol 1980; 7: 243-355.

[10]. Burchell RC. Premature spontaneous rupture of the membranes. Am J Obstet Gynec 1964; 88: 251.

[11]. Aktar MS, Degan JS, Aktar UA, D Sharam. PROM: Study of 300 cases and review of literature. J Obstet \& Gynecol of India. 1980; 30: 81 .

[12]. Webster A. Management of premature rupture of fetal membranes. Obstet gynecol Surv 1969; $24: 485$.

[13]. Longlee S, LEE JN. Fetal weight and PROM IN preterm delivery. Asia Oceania.J Obstet and Gynecol Surv 1986; $21: 400$.

[14]. Nelson, Arias Fernando. Study of premature rupture of membranes. Obstet Gynaecol Surv 1986; $21: 400$.

[15]. Kappy Kenneth A, Cetrulo Curtis, Robert LK. A premature rupture of membranes. A conservative approach. Am J Obstet Gynecol 1979; 134(6): 655-661.

[16]. Gunn GC, Mishell DR, Morton DG. Premature of membranes, a review: Am J Obstet Gynec 1970; $106: 469$.

[17]. Friedman ML, McElin TW. Diagnosis of ruptured fetal membranes. Am J Obstet Gynecol 1969; 104: 545-550.

[18]. Bourne et al. Management of premature rupture of membranes. Obstet and Gynecol 1976; 153: $37-40$.

[19]. Grant John, Keirse Marc JNC. Prelabour rupture of membranes. Effective care in pregnancy and childbirth. Oxford: Oxford university Press, 1989; 1112-1117.

[20]. Russell KP, Anderson GVT. The aggressive management of ruptured membranes. Am J Obstet Gynecol 1962; 83: 930-1962.

[21]. Embrey M. Premature rupture of the membranes. J Obstet Gynecol.Br Emp 1953; 60: 37.

[22]. Alger LS, Pupkin MJ. Etiology of premature rupture of membranes. Clin Obst Gynecol 1986; 29(4): 758.

[23]. Kanayama N, Toshihiko T, Kawashima Y, HoriuchiK, Fujimoto D. Collagen types in normal and prematurely ruptured amniotic membranes. Am J Obstet Gynecol 1985; 153: 899-903.

[24]. Artal K, Sokal RJ, Neuman M, Burstein AH, Stojkor J. The mechanical properties of prematurely and non-prematurely ruptured membranes. Am J Obstet Gynecol 1976; 125: 655-659.

[25]. Varner et al. Mechanical properties and collagen types in premature rupture of membranes. AM J Obstet Gynecol 1985; 121: 712715 .

[26]. Sbarra AJ, Selnaraj RJ, Cetrulo CL, Feingold N, Newton E, Thomas GB. Infection and phagocytosis as possible mechanisms of rupture in premature rupture of membranes. Am J obstet Gynecol 1985; 153: 38-454.

[27]. Cederquist et al. Immunological basis of premature rupture of membranes. BJOG 1974; 109: 500-504. 
[28]. Varner MW, Galask RP. Conservative management of premature rupture of membranes. Am J Obstet Gynecol 1981; $140: 39$

[29]. S Akhter, M Rasihd, R Akter et al. Journal of Bangladesh College of Physician Singoel. 2010; $28: 1$.

[30]. Gibbs Ronald S, Blanco Jorge D. Premature rupture of membranes. Obst Gynecol 1982; 60(6): 671-679.

[31]. Newton ER, Prithoda TJ, Gibbs RS. Logistic regression analysis of risk factors for intra-amniotic infection. Obstet Gynecol 1984; 73: 571-5.

[32]. Baptisti A. Clinical test for the determination of ruptured membranes. Am J of Obstet Gynecol. 1938; $35: 688$

[33]. Anjanayulur et al. Jr of Obst Gynecol of India 1970; 17: 170.

[34]. Brosens I, Gorden H. J Obstet \& Gynecol by Commonwealth. 1965; 72: 342.

[35]. Hassan Boskabadi, Gholamani Maamonei, Shahin MaFinejad. Macedonian Journal of Medical Sciences 2011 March 15; 4(1): 9398.

[36]. Gluck L, Kulorich MV. Lecithin/ sphingomyelin ratio in amniotic fluid in normal and abnormal pregnancy. Am J Obstet \& Gynecol. 1979; 135: 64

[37]. Danforth DN et al. Am J Obstet Gynecl. 1953; 65: 480

[38]. Tanir HM, Sener T, Tekin N, Aksit A, Ardic N. PROM \& Neonatal Outcome prior to 34 weeks of Gestation. Int J Gynaecol Obstet 2003; 82(2): 167-72

[39]. Cushner IM, Mellitis D. Obstet Gynecol Survey 1972; 27: 94

[40]. Liggins GC \& Howte RM. J of Paediatrics 1972; 50: 515-25.

[41]. Shehla Noor, Ali Fawwad, Hasan Shahzad, Ruqqia Sullama, Rubina Bashir. Foetomaternal Outcome in patients with or without PROM. Journal Ayur Med.

[42]. Tahir S, Aleem M, Aziz K. Incidence of outcome of PROM. Pak T Med Sci 2002; 18(1): 26-32.

[43]. Charles PJ, Muriel R, Charles PJ, Reni E, Olivienc, Pascal G et al. A prospective population bared study of 598 cams of PROM, description, management and mortality. Eur J Obstet Gynecol Reprod Boil 2005; 121: 164-70.

[44]. Choudhari Snehamay, Mitra Sankanath, Biswas Pranakumar, Bhattacharyya. Sudipta. Journal Obstet Gynecol India 2006 June; 56(3): 224-229.

[45]. Garite TJ, Freeman RK, Dinzey EM, Braly P. Am J Obstet \& Gynecol. 1981; 141: 508.

[46]. Edward R Newton. Clinical Perinatology (2005): 32; 571-600.

[47]. Maric H Yudnic et al. SOGC. Journal Obstet Gynec Jan 2009; 31(9): 863-867.

[48]. Heuback EM, MacDonald HM and Caritis SR Reids. Controversy in Obstet \& Gynecol III. WB Saunderts Co., Phildelphia, 1983: 99.

[49]. Medina TM, Hill DA. PROM: Diagnosis and management. $\quad$ Physician. 2006; 73(4): 659-64.

[50]. Fatemeh Tarassali, Marzieh Ghareni, Ashraf Mohamadradi, Janislih Sharifian. Survey of Pregnancy Outcome in PROM with AFI $<5 \&>5$ OMT. 2010; 25: 118-123.

[51]. F-Nilli \& AA, Shains Ansani. Neonatal complications of premature rupture of membranes. Aeta Medica Irania 2003; $41(3)$ : 176.

[52]. Perikins RP. Neonatal significance of selected perinatal events among Infant of LBW-II. The influence of ruptured membranes. Am J Obst Gynec 1982; 142: 7

Name: IP No. Sl. No.

\section{Proforma}

Age: $\quad$ Date \& Time \& Admission

A) History

Date of discharge

1. Complaints duration

Amenorrhoea

Time of rupture

Labour pains

PV white discharge

Fever

Frequency of coitus previous to rupture

2. Menstrual history LMP EDD

3. Obstetrical history Gravid Para

Previous labour

Abortions

Complications

4. Past history handled outside Yes/ No

B) Examination

General Ht Wt

Pallor BP

Edema

Pulse

Systemic

Temperature

CVS RS

P/A Fundal height

Lie

Position

Contraction 
$\mathrm{P} / \mathrm{s}$

Leak Frank/not obvious leak

Color of liquor Appear on manipulation

$\mathrm{P} / \mathrm{V} \quad$ Cx dilatation:

Effacement

Station

Position

C) Investigation

Membrane

Present/ Absent

$\mathrm{Hb}$

WBC TC

DC

Urine Alb

CRP

Sug

For leak detection

Diagnosis:

1. Litmus paper

D) Management of Delivery

Type + Outcome

1. Conservative Time of delivery

2. Spontaneous

3. Induced with oxytocin

4. Caesarean section - Indication

5. Antibiotics

E) Neonate

Sex M/F
Weight
Gestational age
$\begin{aligned} & \text { Apgar score 1 min } \\ & \text { Congenital abnormalities }\end{aligned}$

Evidence of complications

Neonatal

a) Respiratory distress (RDS)

b) Neonatal sepsis

Pneumonia

Umbilical sepsis

Conjunctivitis

Septicemia

c) Death

Maternal

Cause

1. Evidence of chorioamnionitis
a) Uterine tenderness
b) Temperature
c) Smell of liquor

2. Puerperal infection
a) Pulse
b) Temperature
c) Lochial discharge
Smell

Summary

1. No. of pelvic examination

2. Rupture onset of labour interval

3. Rupture delivery interval

4. Outcome 